\title{
Dissecting Contrasts in Cell Death, Hormone, and Defense Signaling in Response to Botrytis cinerea and Reactive Oxygen Species
}

\author{
Katariina Vuorinen, ${ }^{1}$ Olena Zamora, ${ }^{2}$ Lauri Vaahtera, ${ }^{3}$ Kirk Overmyer, ${ }^{1}$ and Mikael Brosché ${ }^{1,2,+}$ \\ ${ }^{1}$ Viikki Plant Science Centre and Organismal and Evolutionary Biology Research Program, Faculty of Biological and \\ Environmental Sciences, University of Helsinki, 00013 Helsinki, Finland \\ ${ }^{2}$ Institute of Technology, University of Tartu, Nooruse 1,50411 Tartu, Estonia \\ ${ }^{3}$ Department of Biology, Faculty of Natural Sciences, Norwegian University of Science and Technology, Trondheim, Norway \\ Accepted 30 September 2020.
}

\begin{abstract}
Plants require interaction between signaling pathways to differentiate and integrate stress responses and deploy appropriate defenses. The hormones ethylene, salicylic acid (SA), and jasmonic acid (JA) are important regulators of plant defenses. Numerous interactions between these signaling pathways are the cornerstone of robust plant immunity. Additionally, during the early response to pathogens, reactive oxygen species (ROS) act as signaling molecules. Here, we examined the extent of signal interaction in the early stages of Botrytis cinerea infection. To enable a comparison between $B$. cinerea infection with ROS signaling, we subjected plants to ozone treatment, which stimulates an apoplastic ROS burst. We used a collection of single, double, and triple signaling mutants defective in hormone signaling and biosynthesis and subjected them to $B$. cinerea infection and ozone treatment at different timepoints. We examined lesion size, cell death, and gene expression (both quantitatively and spatially). The two treatments shared many similarities, especially in JA-insensitive mutants, which were sensitive to both treatments. Unexpectedly, a $B$. cinereasusceptible JA-insensitive mutant (coil), became tolerant when both SA biosynthesis and signaling was impaired (coil npr1 sid2), demonstrating that JA responses may be under the control of SA. Extensive marker gene analysis indicated JA as the main regulator of both $B$. cinerea and ozone defenses. In addition, we identified the transcription factor SR1 as a crucial regulator of PLANT DEFENSIN expression and cell-death regulation, which contributes to resistance to $B$. cinerea. Overall, our work further defines the context of ROS in plant defense signaling.
\end{abstract}

Keywords: cell death, defense signaling pathways, ethylene, fungus-plant interactions, jasmonic acid, salicylic acid

${ }^{\dagger}$ Corresponding author: M. Brosché; mikael.brosche@helsinki.fi

Funding: This work was supported by the Academy of Finland, Center of Excellence in the Molecular Biology of Primary Producers 2014-2019 (decisions 271832 and 307335), an Ella ja Georg Ehrnroothin Säätiö grant to K. Vuorinen, and the University of Helsinki Doctoral Programme in Plant Sciences.

*The $\boldsymbol{e}$-Xtra logo stands for "electronic extra" and indicates there are supplementary figure and supplementary table files published online.

The author(s) declare no conflict of interest.

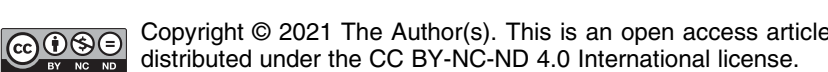

Plants use many different signaling pathways to activate defense signaling in response to their highly dynamic environments. Botrytis cinerea, the causal agent of gray mold, has a broad host range of several hundred species (Williamson et al. 2007) and is important both in the lab, as a model fungal necrotrophic pathogen, and in the field, as a highly virulent pathogen causing great yield losses. Understanding how plants defend against $B$. cinerea is thus of economic importance.

One of the earliest plant responses to pathogen infection is an extracellular burst of reactive oxygen species (ROS) (Torres 2010). Extracellular ROS, including superoxide and hydrogen peroxide, are formed through activation of respiratory burst oxidase homologs (RBOHs) and cell-wall peroxidases (Torres 2010). These ROS have multiple, layered, and complex roles in plant-pathogen interactions. ROS act as mediators of the pathogen-induced cell death termed the hypersensitive responses (HR), increase lignin production to strengthen cell walls, and act as signaling molecules within and between cells (Denness et al. 2011; Moura et al. 2010; Torres 2010). ROS-induced processes are especially complex in the plant interaction with $B$. cinerea; ROS participate in pathogen development (Siegmund and Viefhues 2016) and are produced in the host apoplast by the pathogen as a virulence factor (Govrin and Levine 2000). Further, B. cinerea induces active ROS production by the host plant as well as host HR-like programmed cell death (PCD), which is also mediated by ROS (Torres 2010). While later ROS production acts to promote virulence, very early ROS may act to promote host immunity (Asselbergh et al. 2007; Serrano et al. 2014; Survila et al. 2016). Thus, dissection of the several signaling pathways triggered by necrotrophic pathogens like $B$. cinerea remain a challenge to understanding the complex multigene immunity that protects against them.

One approach to understand the role of ROS in defense signaling is to use treatments with ozone $\left(\mathrm{O}_{3}\right)$. When found in the troposphere, this gaseous molecule is a major air pollutant that causes damage to plants. $\mathrm{O}_{3}$ enters the leaves through stomata and breaks down in the apoplastic space into other ROS. Thus, in the lab $\mathrm{O}_{3}$ is a useful experimental tool to noninvasively induce ROS signaling (Wohlgemuth et al. 2002) in the absence of other complicating pathogen responses, for instance, those triggered by toxins or effectors. Both $B$. cinerea infection and $\mathrm{O}_{3}$ activate HR-like PCD in sensitive genotypes (Govrin and Levine 2000; Overmyer et al. 2005). In plantpathogen interactions, the HR protects plants against biotrophic pathogens. In contrast, inappropriate cell death is considered to leave plants more susceptible to necrotrophic pathogens 
(Govrin and Levine 2000), which feed on dead and dying tissues. An Arabidopsis mutant, defense no deathl (dndl), in which PCD is blocked, is tolerant to both $B$. cinerea and $\mathrm{O}_{3}$ (Govrin and Levine 2000; Overmyer et al. 2005). There is a high level of similarity between the transcriptional responses to $B$. cinerea infection, $\mathrm{O}_{3}$-treatment, and mutants that undergo spontaneous cell death (so called lesion-mimic mutants) (Xu et al. 2015).

Plant hormones such as SA (salicylic acid), JA (jasmonic acid), and ET (ethylene) play crucial roles in plant defenses. JA and ET have been connected, in particular, to defenses against necrotrophic pathogens, whereas SA is important in defenses against biotrophic pathogens, although it also plays some role in the defense against B. cinerea (Ferrari et al. 2003; Zhang et al. 2017). The main SA biosynthesis pathway starts in the chloroplast with ISOCHORISMATE SYNTHASE1 (Wildermuth et al. 2001), while perception and signaling require NONEXPRESSOR OF PR GENES1 (NPR1) and NPR3/NPR4 (Ding et al. 2018). JA is produced from fatty acids ( $\alpha$-linolenic acid) in a multistep pathway taking place in the chloroplast, peroxisome, and cytosol. The biologically active jasmonoylisoleucine is perceived by the receptor CORONATINE INSENSITIVE1 (COI1) to initiate JA signaling. ET is a gaseous hormone, whose perception leads to cleavage of ET INSENSITIVE2 (EIN2) and relocalization of the C-terminal end to the nucleus, where it regulates transcription (Qiao et al. 2012). In addition to SA, JA, and ET, other hormones also affect defense signaling. Auxin is a crucial hormone in several developmental responses, which also modulates defense signaling (Blomster et al. 2011; Leyser 2018; Wang et al. 2007).

Arabidopsis thaliana mutants have been essential to understand hormone signaling in multiple plant-pathogen interactions (Glazebrook 2005). For all three main defense hormones multiple mutants are available with defective biosynthesis, perception, signaling, and transcriptional regulation. These have been instrumental in understanding plant responses to a broad range of pathogens and interaction among signaling pathways (Overmyer et al. 2018). In relation to B. cinerea and $\mathrm{O}_{3}$, JA-insensitive and JA biosynthesis mutants have increased sensitivity to both treatments (Blomster et al. 2011; MéndezBravo et al. 2011; Overmyer et al. 2005; Xu et al. 2015). This indicates that JA co-ordinates defenses both against apoplastic ROS and necrotrophic fungi.

$B$. cinerea infection and $\mathrm{O}_{3}$-induced apoplastic $\mathrm{ROS}$ treatment share many similarities during early stages after stress initiation, including activation of $\mathrm{PCD}$, transcriptional responses, and the requirement of JA for successful defense. Using different approaches, we examined the early stages of defense signaling after these treatments. To identify potential points of signal interaction, we used single, double, and triple mutants with compromised function in one or several signaling or biosynthesis pathways for SA, JA, and ET (coil, ein2, nprl, sid2) (Xu et al. 2015). Furthermore, to evaluate the role of auxin and possible auxin-JA interaction, we included the auxin resistant 1 (axrl) mutant. The axrl mutant is impaired in regulation of SCF (Skp1, cullin, F-box protein) complex activity (Dharmasiri et al. 2007), resulting in both auxin and JA insensitivity (Tiryaki and Staswick 2002). Accurate transcriptional regulation is required for proper $B$. cinerea defenses, illustrated by the isolation of several $B$. cinerea-susceptible mutants encoding transcription factors (TFs) including bos 1 (botrytis-susceptible1) (Mengiste et al. 2003), wrky33 (Liu et al. 2015) and sr1-4D (signal responsive1, also known as calmodulin-binding transcription activator3 (Nie et al. 2012). SR1 regulates SA responses (Du et al. 2009), ET signaling (Nie et al. 2012), and expression of early pathogen-responsive genes (Jacob et al. 2018). As SR1 is suggested to act in multiple signaling pathways, we included the $s r 1-4 D$ mutant that has a dominant mutation that impairs its function (Nie et al. 2012). Comparison with the JA, SA, and ET mutants would further define the signal pathways SR1 regulates to alter hormone responses and $B$. cinerea susceptibility.

While many similarities between the responses to $\mathrm{O}_{3}$-induced ROS and B. cinerea infection were apparent, analysis of the axrl and $s r 1-4 D$ mutants revealed key differences that may indicate $B$. cinerea-specific events within the defense signal network. Our results also emphasize the importance of SA, in addition to $\mathrm{JA}$, in defense against $B$. cinerea.

\section{RESULTS}

\section{SA-JA signaling interactions determine the response to $B$. cinerea.}

To study defense signaling, we established a panel of genetic tools, including several double and triple mutants deficient in multiple hormone signaling pathways (Xu et al. 2015) (Supplementary Table S1). In addition, we generated a new triple mutant, coil nprl sid2, impaired in SA biosynthesis, SA signaling, and JA signaling. This collection together with their wild type (WT), Col-0, was first assayed for their sensitivity to $B$. cinerea, quantified as the size of lesion spread at $48 \mathrm{~h}$ postinfection (hpi) from drop-infected leaves (Fig. 1A and B). The $\operatorname{srl}-4 D$ mutant was sensitive, as was previously observed (Nie et al. 2012). Consistent with the role for JA in B. cinerea immunity, most genotypes bearing coil exhibited enhanced disease sensitivity (EDS). We observed no differences between coil and its higher order mutants with ein 2 , sid2, and ein 2 sid2, suggesting that JA is the prime regulator of the $B$. cinerea response. However, in the coil nprl sid2 triple mutant, deficient in both SA biosynthesis and signaling, the EDS phenotype of coil was rescued. Further analysis showed that the coil nprl double mutant exhibited a $B$. cinerea EDS phenotype similar to that of coil (Fig. 1C). Overall, this indicates that the strong EDS phenotype conferred by loss of JA signaling function (i.e., coil) may be dependent on SA biosynthesis and signaling.

Genotypes with a $B$. cinerea response similar to that of WT were axr1, ein2, npr1, sid2, and ein2 sid2. Similar to coil, the axrl mutant is JA-insensitive (Tiryaki and Staswick 2002) and $\mathrm{O}_{3}$-sensitive (Blomster et al. 2011). In contrast, its response to $B$. cinerea was not altered. AXR1 functions to regulate the CULLIN subunit of SCF-COI1 (and in addition several other SCF complexes). The absence of an EDS phenotype in axrl suggests that either its JA insensitivity is weaker than coil (Tiryaki and Staswick 2002) or that its interactions with other signaling pathways, such as auxin, alter its response to $B$. cinerea infection.

\section{Comparing B. cinerea susceptibility to apoplastic ROS induced cell death.}

Treating plants with $\mathrm{O}_{3}$ initiates an apoplastic ROS burst that causes HR-like cell-death lesions in sensitive genotypes (Overmyer et al. 2005; Wohlgemuth et al. 2002). We compared the $B$. cinerea EDS phenotypes (Figs. $1 \mathrm{~B}$ and $\mathrm{C}$ ) with the $\mathrm{O}_{3}$ sensitivity of the same mutants, using data from both our previous studies on $\mathrm{O}_{3}$ (Blomster et al. 2011; Xu et al. 2015) and new experiments (Supplementary Fig. S1). To facilitate comparison between these treatments and mutants, the extent of $\mathrm{O}_{3}$ cell death quantified with ion leakage was recalculated into a sensitivity ratio by dividing the effect of treatment with control and then comparing that ratio to Col- 0 . For $B$. cinerea, the fold change ratio was calculated by comparing lesion sizes in mutants to those of Col-0. Generally, $\mathrm{O}_{3}$-sensitivity correlated with susceptibility to $B$. cinerea, as observed in coil, coil ein2, coil sid2, and coil ein2 sid2 (Fig. 2). Similarly, the $\mathrm{O}_{3}$-tolerant 
genotypes, Col-0, ein2, npr1, sid2, and ein2 sid2 were resistant to $B$. cinerea. However, three mutants did not follow this pattern; $s r 1-4 D$ was $\mathrm{O}_{3}$-tolerant and susceptible to $B$. cinerea and, conversely, $\mathrm{O}_{3}$-sensitive axrl and coil nprl sid 2 were resistant to $B$. cinerea (Fig. 2). We previously speculated that the $\mathrm{O}_{3}$ sensitivity of axrl was due to its JA insensitivity (Blomster et al. 2011), but this seems unlikely, given its $B$. cinerea tolerance (Fig. 1). Another common cause of $\mathrm{O}_{3}$ sensitivity is defective stomatal regulation resulting in increased $\mathrm{O}_{3}$ uptake (Brosché et al. 2010). However, stomatal conductance in axrl was similar to that of WT, excluding a role for altered $\mathrm{O}_{3}$ uptake in the $\mathrm{O}_{3}$ sensitivity of $\operatorname{axrl}$ (Supplementary Fig. S2). Alternatively, the $\mathrm{O}_{3}$ sensitivity of axrl could be related to its altered expression of genes regulating cell death (Kaurilind and Brosché 2017).

\section{Gene expression in response to $B$. cinerea infection and apoplastic ROS.}

An important part of defense to pathogens and other stresses is altered transcriptional programs. We used RNA-seq data to globally compare the early transcriptional response to B. cinerea (14 h) (Liu et al. 2015) and $\mathrm{O}_{3}$ (2 h) (Xu et al. 2015). Note that different growth conditions were used in these two studies, which may influence the comparison of differentially regulated genes. At a twofold cutoff, approximately $45 \%$ of genes were regulated similarly by the two treatments (Fig. 3). This large overlap further suggests that plant defenses to B. cinerea, at least in part, is mediated through ROS. Importantly, very few genes had transcript levels with opposite regulation by the two treatments, i.e., increased expression by one treatment and reduced transcript levels by the second treatment (Fig. 3).

To investigate early interactions in the plant signaling network, we used real time reverse transcription quantitative PCR (qPCR) with 13 genes selected to reflect SA, JA, ET, and other defense signaling pathways (Brosché et al. 2014; Xu et al. 2015). Markers used were ARGOS (AUXIN-REGULATED GENE INVOLVED IN ORGAN SIZE) (Xu et al. 2015; Hillmer et al. 2017) for ET; JAZ1 (JAZMONATE-ZIM PROTEIN 1), PDF1.2 (PLANT DEFENSIN 1.2), and RAP2.6 (RELATED TO
A
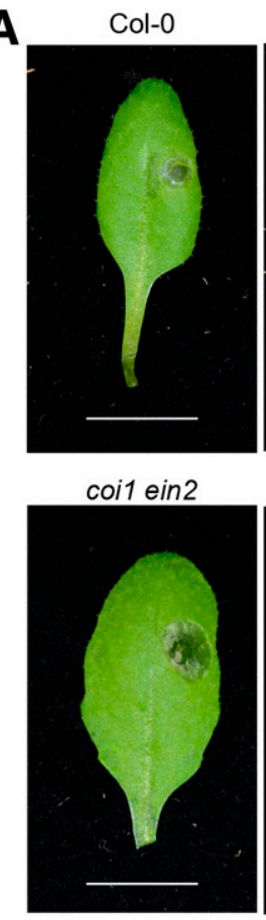

B

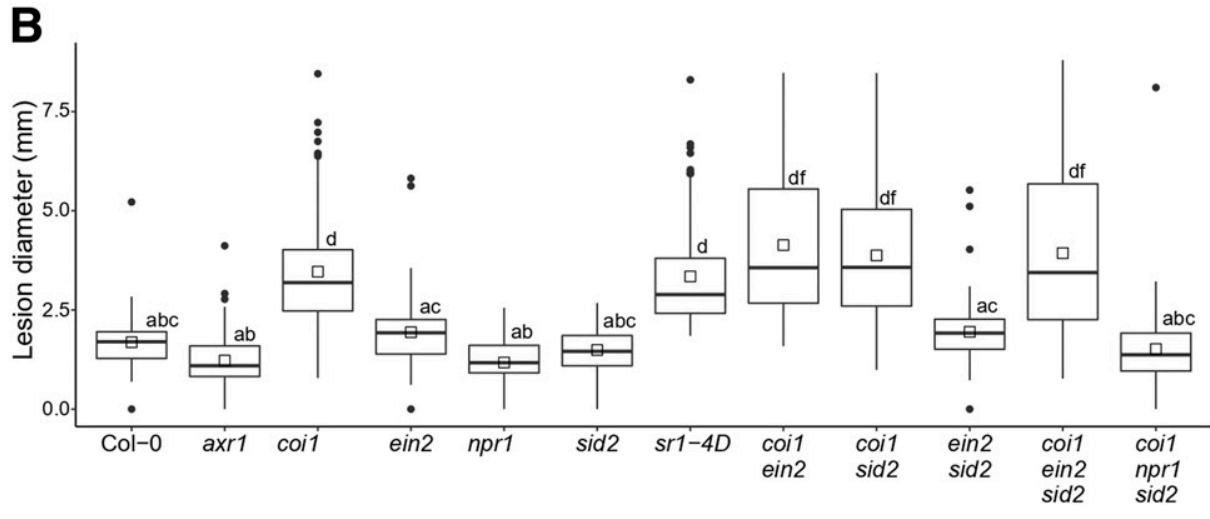

coi1

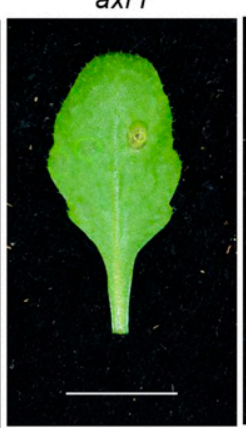

coi1 sid2

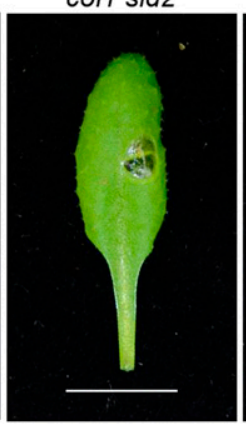

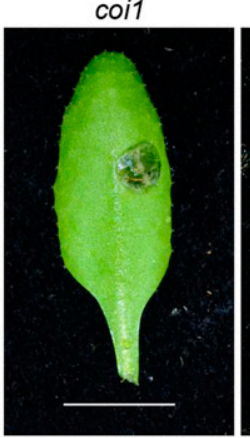

ein2 sid2

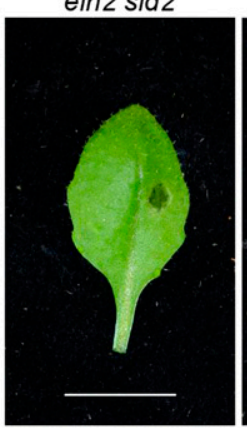

ein2

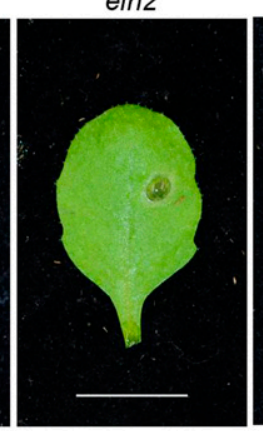

coi1 ein2 sid2

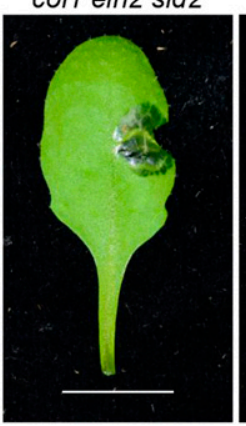

npr1

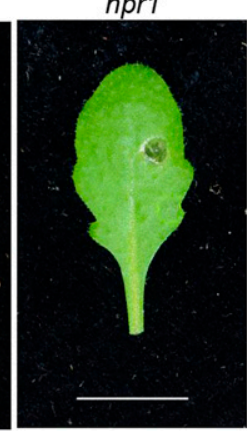

coi1 npr1 side

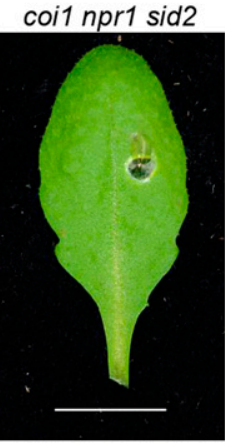

sid2

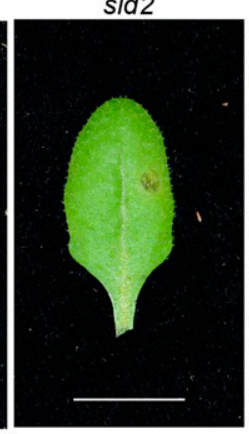

coi1 npr1

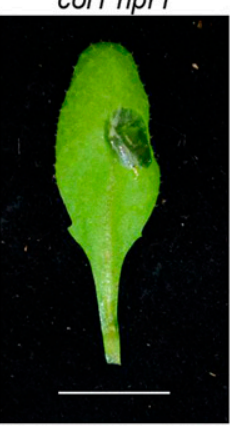

sr1-4D

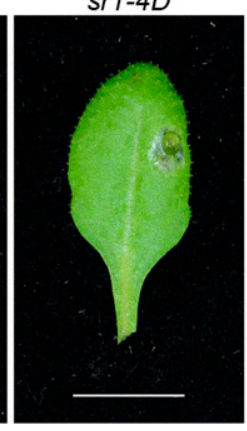

C

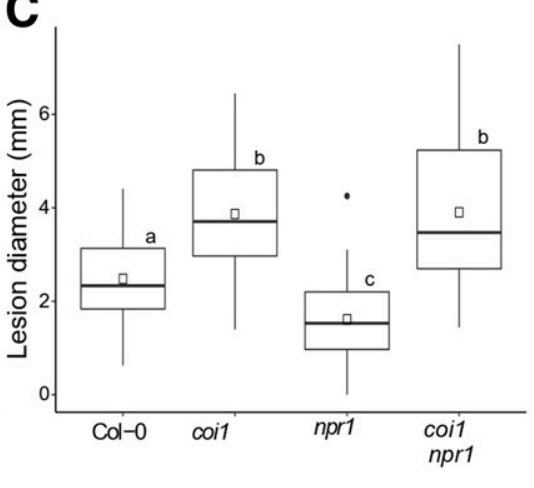

Fig. 1. Signaling mutant response to Botrytis cinerea infection. Three-week-old signaling mutants and wild-type (WT) Col-0 plants were drop-inoculated with B. cinerea. Lesion diameters were quantified $48 \mathrm{~h}$ postinfection. A, Representative $B$. cinerea lesions on WT and mutants. Scale bar $=1 \mathrm{~cm}$. B, Size of spreading $B$. cinerea lesions from drop-infected leaves. Data are displayed as box plots of four pooled independent biological repeats, total $n=85$ per genotype. Letters above box plots indicate significance groups among genotypes (mixed linear model, Tukey test, $P<0.05$ ). C, Additional phenotyping was performed to determine the effect of coil-16 nprl on the phenotype of coil-16 nprl sid2 (three repeats, $n=79$ ). 
AP 2.6) for JA; ICS1 (ISOCHORISMATE SYNTHASE 1), PR-1 (PATHOGENESIS-RELATED 1), and WRKY38 (WRKY DNABINDING PROTEIN 38-importantly, WRKY38 is a direct target of NPRI (Wang et al. 2006)-for SA; and FMOI (FLAVIN-DEPENDENT MONOOXYGENASE 1) (Hartmann et al. 2018) for systemic signaling. To expand the range of marker genes, we also included the following genes that display increased transcript levels after pathogen infection: $A B C G 4 O$ (ATP-binding cassette G40, which functions as an abscisic acid (ABA) transporter (Kang et al. 2010)), WRKY75 (ARABIDOPSIS THALIANA WRKY DNA-BINDING PROTEIN 75), PME17 (PECTIN METHYLESTERASE 17), At4g16260 (a putative $\beta$-1,3-endoglucanase) and PDF1.1 (PLANT DEFENSIN 1.1).

We validated the chosen marker genes with analysis of expression data in response to infections with necrotrophic fungi, $\mathrm{O}_{3}$, hormone treatments, and abiotic stress in the Genevestigator database (Supplementary Fig. S3) (Hruz et al. 2008). As expected, hormone marker genes were regulated by their corresponding treatment and all selected marker genes exhibited strong induction by both $B$. cinerea and $\mathrm{O}_{3}$, with a few exceptions. The ET marker $A R G O S$ was only weakly induced by
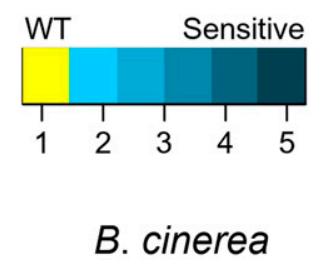

\section{Ozone}

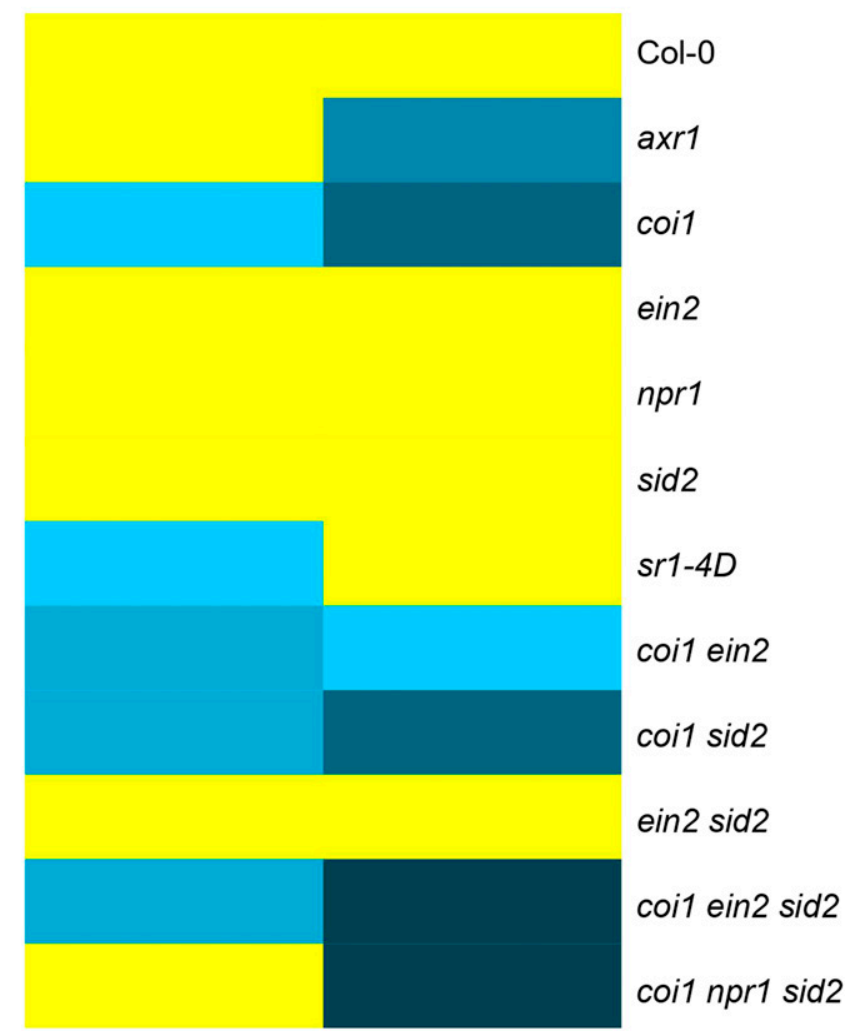

Fig. 2. Comparison of Botrytis cinerea susceptibility and ozone sensitivity. $B$. cinerea fold changes (lesion size compared with Col-0) are based on data from three-week-old signaling mutants and wild-type (WT) Col-0 plants drop-inoculated with $B$. cinerea. Ozone fold change cell death data (measured as ion leakage and normalized to Col-0) is pooled from studies by $\mathrm{Xu}$ et al. (2015) (Col-0, coil, ein2, sid2, coil ein2, coil sid2, ein2 sid2, coil ein2 sid2), Brosché et al. (2014) (nprl), and our original data (axr1, sr1-4D, coil npr1 sid2).
B. cinerea and $\mathrm{O}_{3}$ induced higher expression levels of $P R-1$ only at a late timepoint (Supplementary Fig. S3).

Gene expression in WT. The effect of $\mathrm{O}_{3}$ treatment and $B$. cinerea infection on marker gene expression was quantified with qPCR. We first analyzed the response in Col-0 under $\mathrm{O}_{3}$ treatment using a 2-h timepoint (Fig. 4), which has the maximum number of genes responding to $\mathrm{O}_{3}$ (Blomster et al. 2011). For B. cinerea infections, we used 18 and 24 hpi as early timepoints (Fig. 4).

The $\mathrm{O}_{3}$ treatment caused a strong induction of defense genes at $2 \mathrm{~h}$, except for the late timepoint SA marker genes $P R-1$ and WRKY38 (Fig. 4). Response to B. cinerea infection was greater in the 24 hpi timepoint than at $18 \mathrm{hpi}$, with the exception of two plant defensins, $P D F 1.1$ and $P D F 1.2$. Infection with $B$. cinerea did not increase transcript levels for SA signaling (WRKY38, $P R-1)$, SA biosynthesis (ICS1), or ET (ARGOS). The expression levels obtained with qPCR matched those seen in Genevestigator, taking into account the limited scale $\left(\log ^{2} \leq 2.5\right.$-fold change) used in Genevestigator.

Gene expression in mutants. The relative expression in control and treatment for each mutant was compared with the corresponding WT to identify significant differences. The data are presented separately for B. cinerea (Fig. 5, 24 hpi; Supplementary Fig. S4, 18 hpi) and $\mathrm{O}_{3}$ (Fig. 6).

Transcript levels of $A R G O S$ were induced by $\mathrm{O}_{3}$ in WT and was EIN2-dependent (Fig. 6). In contrast, expression levels of $A R G O S$ were not increased by $B$. cinerea, suggesting that ET signaling is not strongly activated during $B$. cinerea infection at the observed timepoints. Results with higher order mutants of ein2 suggest no interaction between ET and JA or SA in regulation of $A R G O S$ expression.

$J A Z 1, P D F 1.2$, and RAP2.6 were not induced in coil, indicating their strong dependency on functional JA signaling (Figs. 5 and 6). Similarly, PDF1.1 transcript levels were lower in coil genotypes. WRKY75 transcript levels were lower in the JA mutants, indicating they were JA regulated. The axrl mutant had a pattern similar to coil in expression levels for $P D F 1.2$ and WRKY75 but not RAP2.6 or JAZ1. This suggests that axr1 is a weaker JA-insensitive mutant compared with coil.

$P R-1$ and $W R K Y 38$ were not induced in $n p r l$ and sid 2 by $B$. cinerea infection or $\mathrm{O}_{3}$ treatment, which confirmed their regulation by SA signaling (Figs. 5 and 6 ). Expression levels of ICS1 were significantly increased after $B$. cinerea infection in coil and by $\mathrm{O}_{3}$ treatment in axrl and coil, indicating an antagonistic action of JA on SA signaling. $P R-1$ expression levels

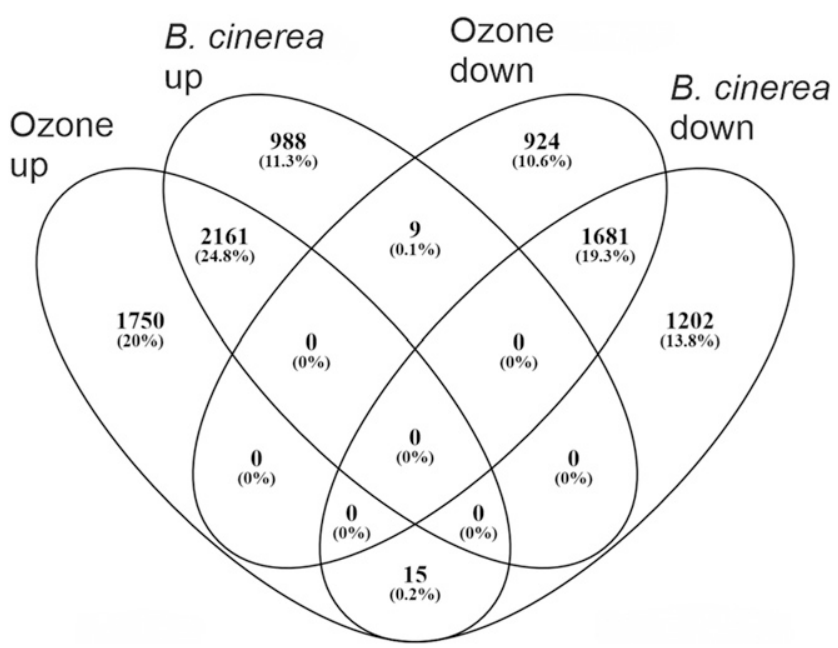

Fig. 3. Venn diagram comparison of 2-h $\mathrm{O}_{3}$ and 14-h Botrytis cinerearegulated genes. Genes were selected at $q<0.05$ and twofold regulation. 
were enhanced in $\operatorname{axr} 1$ and ein2 by $B$. cinerea and in ein 2 by $\mathrm{O}_{3}$, suggesting an inhibitory role for ET on SA signaling. Similarly, WRKY38 had a higher induction by both $B$. cinerea and $\mathrm{O}_{3}$ in ein2. Transcript levels for ICS1 were significantly higher in coil ein 2 by both $\mathrm{O}_{3}$ and $B$. cinerea, pointing toward a joint inhibitory role for JA and ET on SA biosynthesis.

FMO1 was used as a marker gene for systemic signaling (Hartmann et al. 2018) and was induced by both B. cinerea and $\mathrm{O}_{3}$. Expression of FMOI was not dependent on any single signaling pathway.

Expression levels of $A B C G 40$ were not affected in single mutants but showed reduced induction by $\mathrm{O}_{3}$ in double and triple mutants (Fig. 6). However, levels of this transcript remained high also in triple mutants, indicating that its regulation was largely hormone-independent. Similarly, PME17 transcript levels were mostly independent of hormone signaling. Transcript levels for At4g16260 strongly increased in WT but it had lower induction by $B$. cinerea in all single mutants, particularly in $\operatorname{axr} 1, \mathrm{coil}$, and ein2. Induction by $\mathrm{O}_{3}$ was lower in $\operatorname{axr} 1$, ein2, and $s r 1-4 D$.

The srl-4D mutant is impaired in induction of early pathogen-responsive genes (Jacob et al. 2018). In our data, srl$4 D$ strongly impaired accumulation of $P D F 1.1$ and $P D F 1.2$ but not any other JA, SA, or ET marker genes. As plant defensins are thought to provide resistance against fungal pathogens (Thomma et al. 2002), their low expression in $s r 1-4 D$ could at least partially explain the high $B$. cinerea sensitivity of this mutant (Fig. 1).

\section{Spatial expression of defense signaling.}

To complement the quantitative measurements of gene expression levels obtained by qPCR, histological staining of promoter:reporter plants was used to capture spatial resolution of marker gene expression. We obtained or created plants with a selection of promoters from the above marker genes fused to the -uidA reporter producing $\beta$-glucuronidase (GUS) (the lines used are listed in Supplementary Table S1). We examined the expression pattern at several timepoints after B. cinerea, $\mathrm{O}_{3}$, SA, JA, and wounding treatments (Fig. 7). For the promoterGUS lines created for this study (ABCG40, PME17, PDF1.1, At4g16260) and for RAP2.6:GUS, we used two independent lines. To summarize the data, the extent of GUS staining was classified into treatment-specific or -unspecific staining and the treatment-specific staining was assigned into expression classification classes ranging from none (0) to faint (1) to strong (2), using three biological repeats resulting in a numerical score for each promoter-GUS line and treatment (Fig. 7). Representative GUS stains for all lines and treatments are displayed in Supplementary Figure S5.

We used 1 and $6 \mathrm{~h}$ as timepoints for $\mathrm{O}_{3}$ and wounding. For SA and JA, we used 6 and 24 h. In B. cinerea infection we used 18 and 24 hpi. B. cinerea, SA, and JA were administered as drops on leaf surfaces. Wounding was performed as small scalpel cuts or crushing damage with tweezers. These four highly localized treatments could be examined for potential cell-to-cell signaling. In contrast, $\mathrm{O}_{3}$ as a gas was expected to be in contact with the entire rosette.

Most of the marker genes followed the regulation seen with qPCR (Figs. 4, 5, and 6). The pathogen induced genes-ABCG40, At4g16260, PDF1.1, and PME17-displayed a strong GUS stain induced by $B$. cinerea and $\mathrm{O}_{3}$ but also by JA, SA, and wounding. ICS1 was only induced by $\mathrm{O}_{3}$ and SA treatment, which followed the expression levels we observed with qPCR. The JA marker JAZl could be visualized in all treatments,

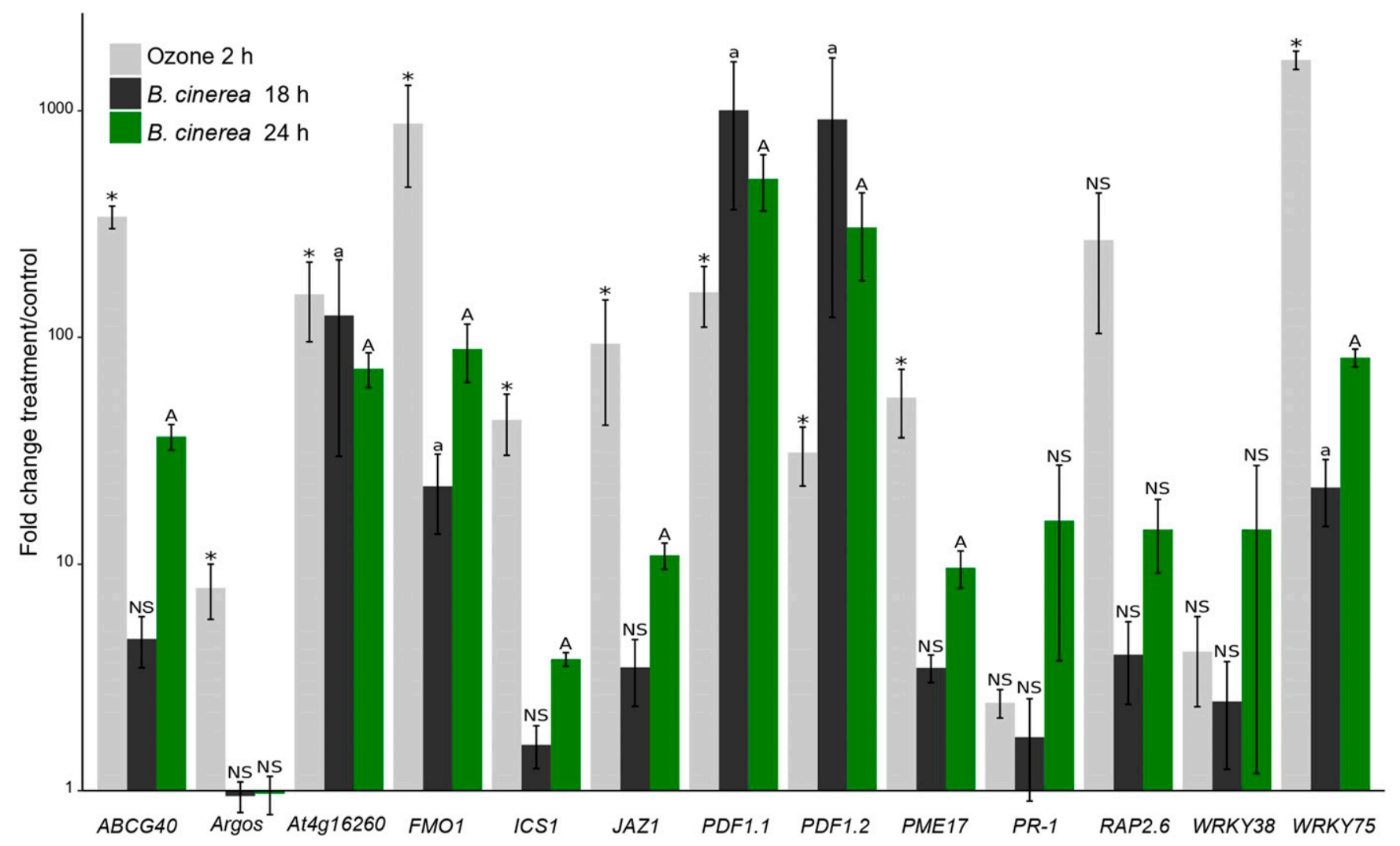

Fig. 4. Marker gene expression (fold change) determined with quantitative PCR in response to Botrytis cinerea infection (18 and $24 \mathrm{~h}$ postinfection [hpi]) and ozone treatment $(2 \mathrm{~h})$ in Col- 0 . Values are means \pm standard error, $n=3$ and displayed on $\log 10$ scale to account for the very large variation in expression levels between different marker genes. Statistically significant differences $(P<0.05$, mixed linear model, Tukey test) is indicated with an asterisk $(*)$ for ozone, a for B. cinerea $18 \mathrm{hpi}$, and A for B. cinerea 24 hpi. 
which was consistent with induction by abiotic stress in Genevestigator data (Fig. 3), indicating that JA signaling is activated in many stress treatments. The GUS stain pattern for WRKY75 indicated more specific regulation of this gene, as its expression was not observed after wounding, JA treatment, or at the early SA timepoint. In contrast, our qPCR data showed that the expression of WRKY75 was dependent on functional JA signaling (Figs. 5 and 6). In addition to JA, expression of WRKY75 is also controlled by SA and Protein Phosphatase $2 \mathrm{~A}^{-\mathrm{B}^{\prime} \gamma}$ (Durian et al. 2020). Thus, regulation of WRKY75 transcript levels is likely to be under the control of several signaling pathways and highly elevated transcript levels might require activation of both $\mathrm{SA}$ and JA signaling.

\section{Role of $s r 1-4 D$ in cell death.}

The $s r 1-4 D$ mutant is B. cinerea susceptible (Fig. 1) and has impaired regulation of early pathogen-induced genes (Jacob et al. 2018) and low expression of PDF 1.1 and PDF1.2 (Figs. 5 and 6). However, transcript levels for SA, JA, and ET marker genes were not altered in $\operatorname{srl-4D}$ (Figs. 5 and 6). To get a
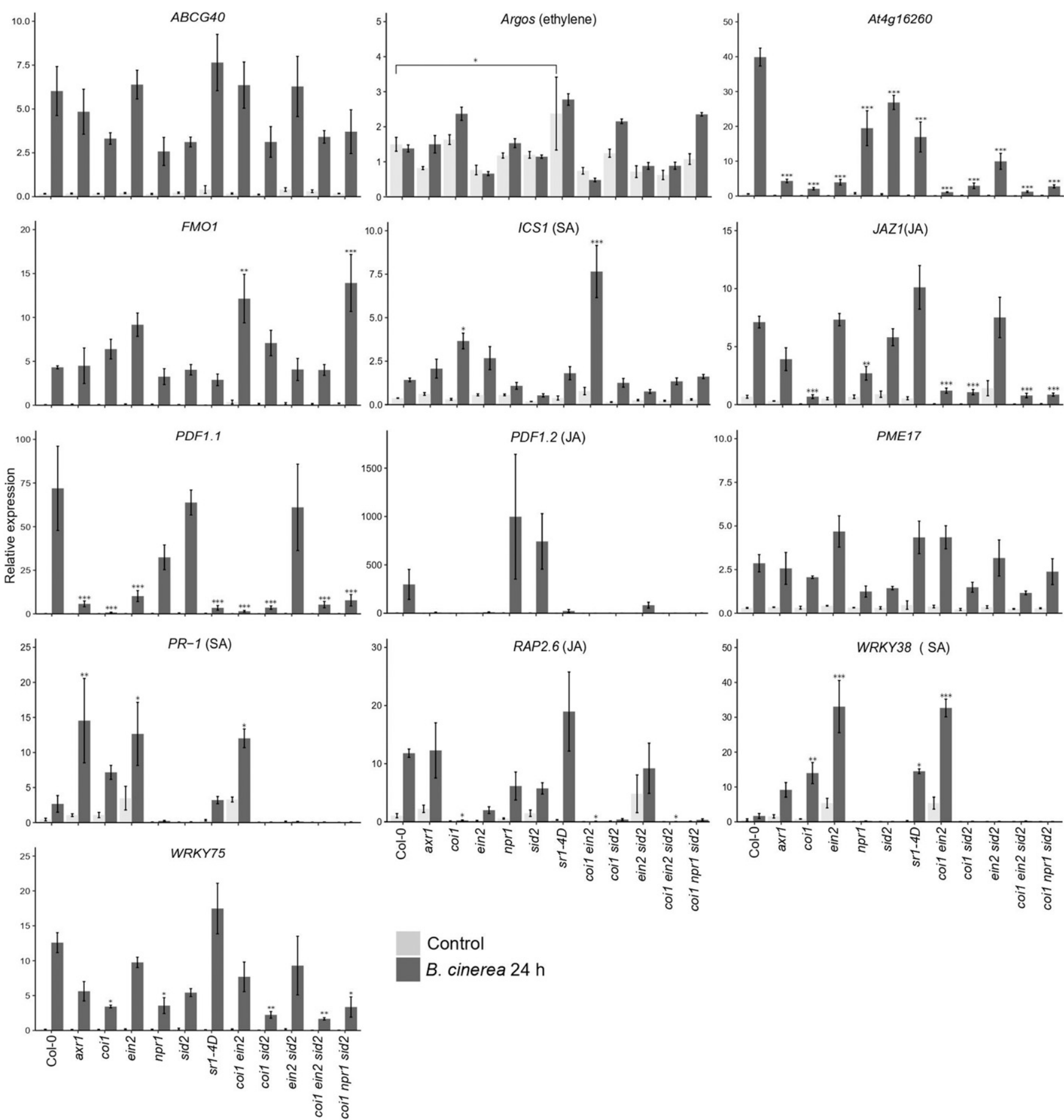

Fig. 5. Marker gene expression in signaling mutants after 24-hpi (h postinfection) Botrytis cinerea infection. Relative gene expression was determined by quantitative PCR after spray-infection with $B$. cinerea spore solution or control media and was normalized to the three reference genes ( $P P 2 A A 3, T I P 41, Y L S 8)$. Values are means \pm standard error, $n=3$. Significances of comparisons of the mutants to the wild type (Col- 0$)$ within treatment and control, respectively, are displayed as asterisks above columns (one asterisk [*]: $P<0.05$, two [**]: $P<0.01$, three [***]: $P<0.001$; three replicates, mixed linear model, Tukey test). 
broader view of which biological processes are controlled by SR1, we crossed $s r 1-4 D$ with lesion mimic mutant acd5 (Liang et al. 2003) and the constitutive defense mutant mpk4 (Petersen et al. 2000). The srl-4D mutation largely reduced the amount of cell death in acd5 and rescued the small size of $m p k 4$ (Fig. 8). This indicates that SR1 also regulates genes related to execution of cell death in addition to regulation of early pathogenrelated genes (Jacob et al. 2018) and plant defensin genes (Figs. 5 and 6). As appropriate cell death control is important for B. cinerea infection (Cui et al. 2019), this could also contribute to the $B$. cinerea sensitive phenotype of the $s r 1-4 D$ mutant.

\section{DISCUSSION}

Hormone interactions in the response to $B$. cinerea.

Plant defenses against pathogens use a signaling network in which JA, SA, ET, and ROS play prominent roles. The final output from defense signaling must be tailored toward the specific pathogen. For example, enhanced PCD is an appropriate response to biotrophic pathogens but may benefit necrotrophic pathogens (Govrin and Levine 2000). Interactions between SA and JA are central to the fine tuning of signaling (Fig. 9), in which SA alters the expression of a large proportion
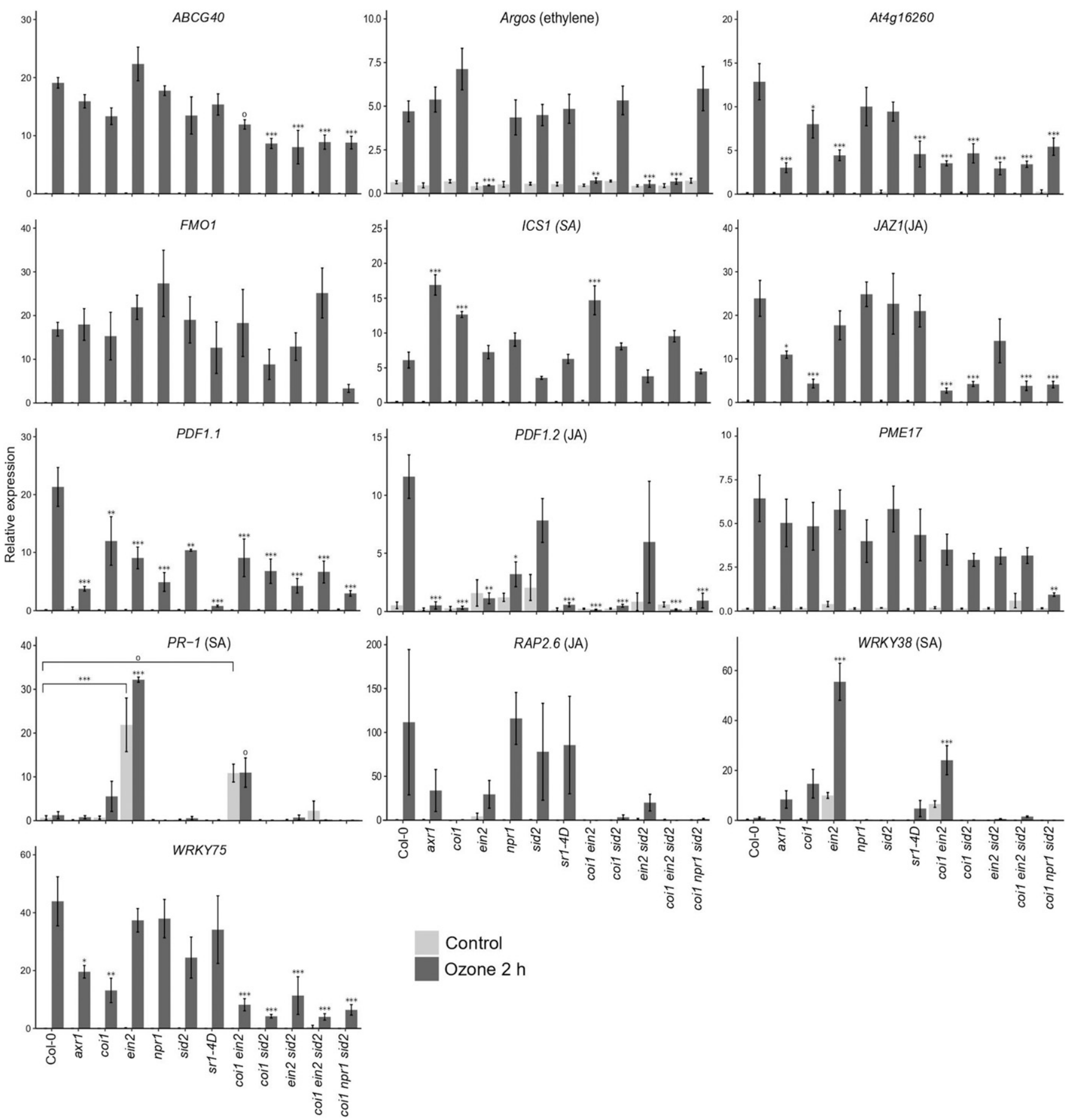

Control

Ozone $2 \mathrm{~h}$

Fig. 6. Marker gene expression in signaling mutants after 2-h treatment with ozone at $350 \mathrm{nl} \mathrm{l}^{-1}$. Relative gene expression was determined by quantitative PCR and was normalized to the three reference genes $(P P 2 A A 3, T I P 41, Y L S 8)$. Values are means \pm standard error, $n=3$. Significances displayed as asterisks above columns (one asterisk [*]: $P<0.05$, two [**]: $P<0.01$, three [***]: $P<0.001$; mixed linear model, Tukey test) are of comparisons of the mutants to wild type (Col-0) within treatment and control, respectively. 
of JA-regulated genes (Hickman et al. 2019). The impact of JA and $\mathrm{SA}$ on the $B$. cinerea-Arabidopsis interaction was previously studied in large scale, using 96 different $B$. cinerea isolates and the coil-1 and nprl mutants (Zhang et al. 2017). Consistent with the established role for JA, most isolates showed increased lesion size in coil. The responses in nprl were more variable, with some isolates showing increased lesion size and others WT size or even smaller. This indicates a genotype-dependent role for SA, which can be further evaluated with higher order mutants with defects in several signaling pathways. This strategy was previously used to dissect interactions among SA, JA, ET, and the regulator PHYTOALEXIN
DEFICIENT4 (PAD4) in response to Pseudomonas syringae and Alternaria brassicicola infection (Tsuda et al. 2009). Signaling from all the hormones contributed to resistance (Tsuda et al. 2009).

In our mutant panel, infection of single mutants revealed responses consistent with previous studies. The $B$. cinerea B05.10 isolate used in this study had increased lesion size in coil, while the nprl mutant was similar to that in WT (Fig. 1). Similarly, the srl-4D mutant also had increased lesion size (Fig. 1), consistent with previous results (Nie et al. 2012). These robust responses observed in single mutants allowed us to use double and triple mutants to explore the interactions
A
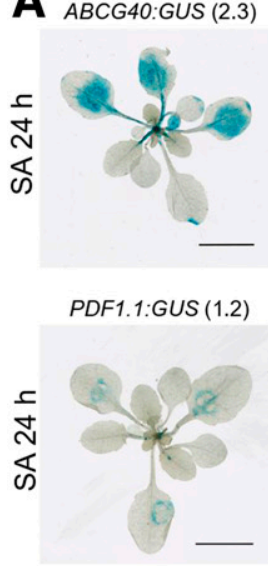

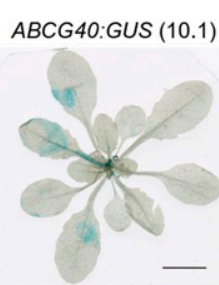

PDF1.1:GUS (3.5)

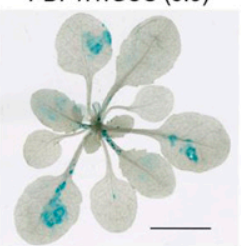

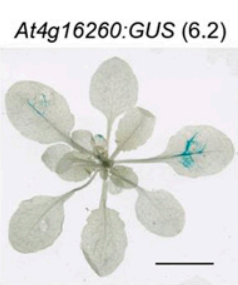

PME17:GUS (2.2)

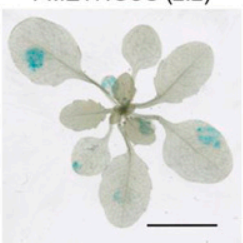

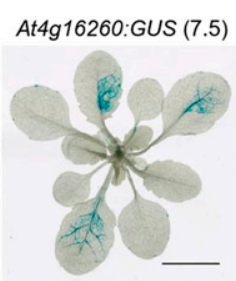

PME17:GUS (8.5)

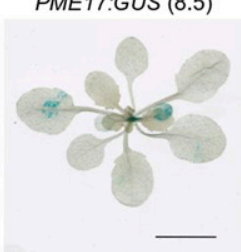

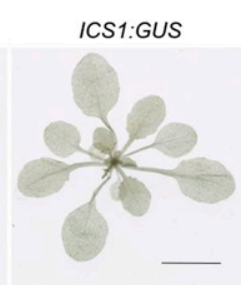

RAP2.6:GUS (1)

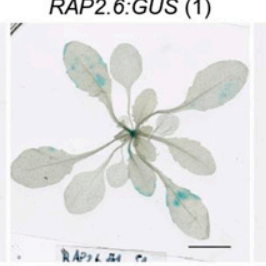

JAZ1:GUS

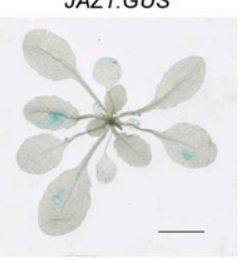

RAP2.6:GUS (2)

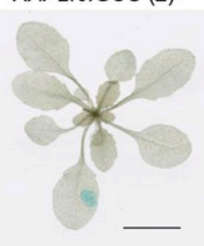

WRKY75:GUS

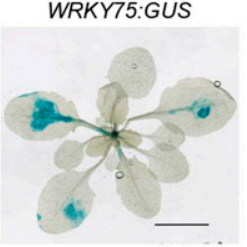

B
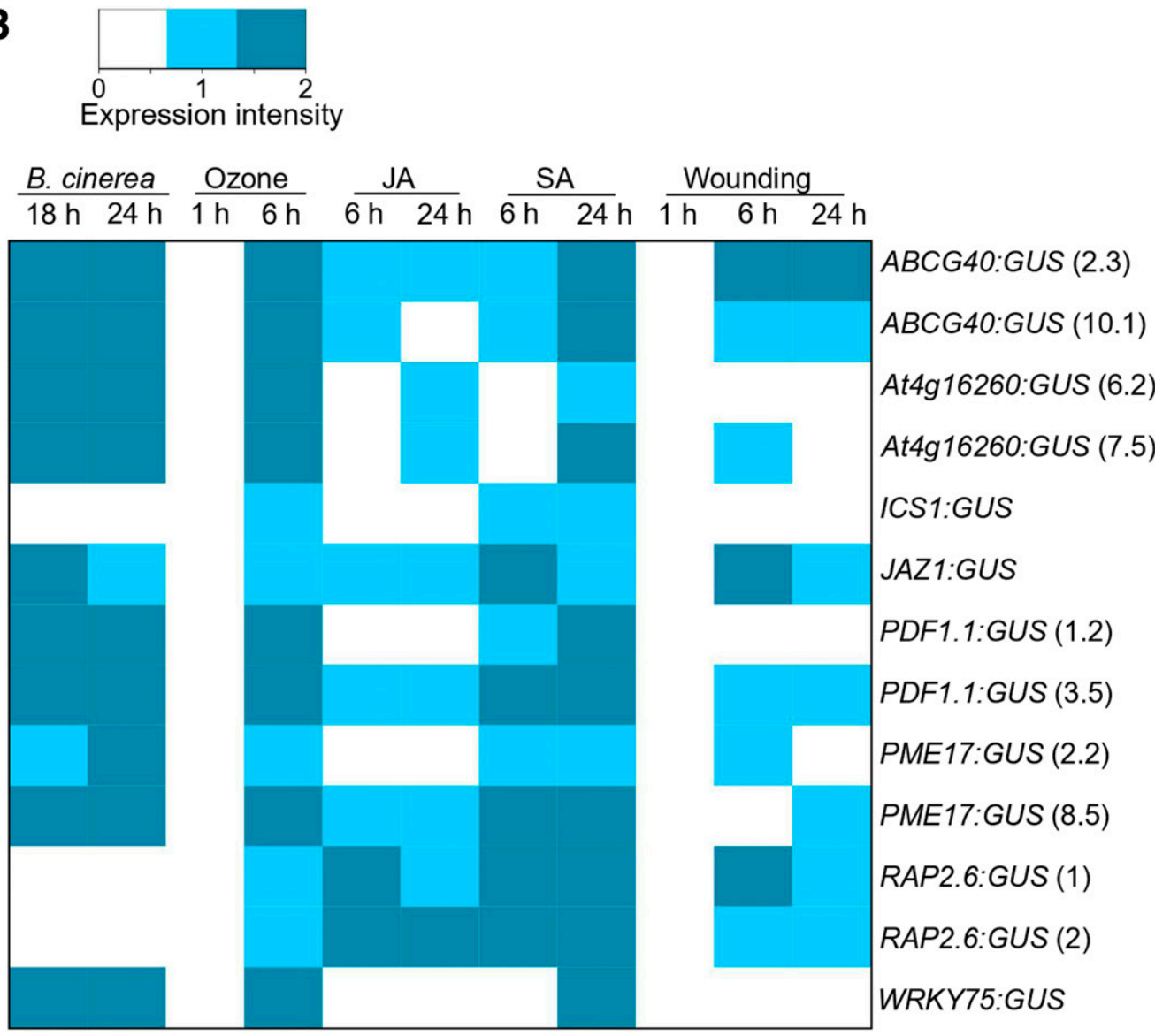

Fig. 7. Visualization of stress marker gene expression with promoter $\beta$-glucuronidase (GUS) staining. A, Representative pictures of the salicylic acid (SA) treatment $(500 \mu \mathrm{M}, 24 \mathrm{~h})$ in all promoter:GUS lines. B, Summary of treatment-specific GUS expression at early and late timepoints. The displayed average of three repeats is calculated from stain intensity score values $(0=$ no staining, $1=$ faint staining, $2=$ strong staining $)$ determined by visual evaluation. 
between JA, SA, and ET. In double mutants, JA was the main determinant of $B$. cinerea immunity, as the different combinations of coil paired with other mutants (nprl, sid2, ein2) all shared the EDS phenotype (Fig. 1).

For the triple mutants, coil ein2 sid2 was as susceptible to $B$. cinerea as coil, further suggesting that SA and ET do not modify the $B$. cinerea susceptibility conditioned by coil. Unexpectedly, coil nprl sid2 was B. cinerea-resistant, which was not seen in coil sid2 or coil nprl (Figs. 1 and 9). SA biosynthesis takes place through two pathways, mediated by ICS 1 and phenylalanine ammonia lyase (Lefevere et al. 2020), while SA signaling is initiated through receptors NPR1, which is a positive regulator of SA signaling, as well as NPR3 and NPR4, which are negative regulators of SA signaling (Ding et al. 2018). There are also NPR1-independent SA-response pathways, for instance, the SA-induced DNA damage pathway (Yan et al. 2013) and SA-binding proteins including CATALASE2 (Yuan et al. 2017) and PROTEIN PHOSPHATASE 2A (Durian et al. 2016; Tan et al. 2020). Hence, there are several candidate processes that could explain the resistance phenotype of coil nprl sid2. i) One of the above mentioned NPR1-independent SA-signaling pathways may participate in the $B$. cinerea response. ii) The SA receptors NPR3 and NPR4 can activate early JA signaling independent of COI1 (Liu et al. 2016). In coil nprl sid2, when both SA levels are low and NPR1 is missing, the function of remaining SA receptors NPR3 and NPR4 might expand to also regulate some aspects of JA defenses. However, as gene expression in coil nprl sid 2 with the marker genes used here was not strikingly different from the corresponding single and double mutants (Figs. 5 and 6), more comprehensive methods such as RNA-seq would be required to find genes that are specifically regulated in coil nprl sid2. 3. The JA-precursor OPDA (12-oxophytodienoic acid) can provide protection from necrotrophic pathogens and activates COI1-indepdent defense signaling (Stintzi et al. 2001). As possible antagonistic effects of SA on JA have been removed in the triple mutant coil nprl sid2, it could be that the efficacy of OPDA signaling is enhanced in this mutant background and is sufficient to activate

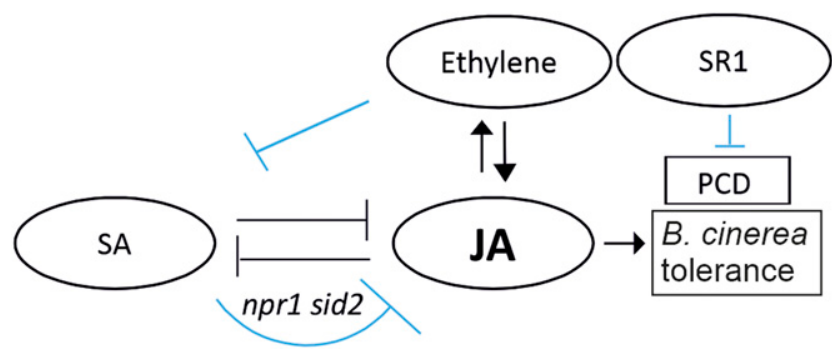

Fig. 9. Plant defense to pathogens and regulation of programmed cell death (PCD) both involve interactions among plant hormones. These include positive interactions between ethylene (ET) and jasmonic acid (JA) as well as inhibitory interactions between salicylic acid (SA) and JA. Primary interactions found in this study are indicated in blue. JA is the main regulator of tolerance to both Botrytis cinerea and $\mathrm{O}_{3}$, however B. cinerea susceptibility of the coil mutant was restored to wild type in coil nprl sid2, thus indicating that the response to JA is under control of SA biosynthesis and signaling. In addition, regulation of SA marker genes is inhibited by ET. The SR1 transcription factor regulates both expression of PLANT DEFENSIN genes and PCD, thus influencing $B$. cinerea tolerance. Note, this figure highlights selected pathways. Interactions among plant signaling networks involve additional components (not shown) and may change over time (Overmyer et al. 2018).
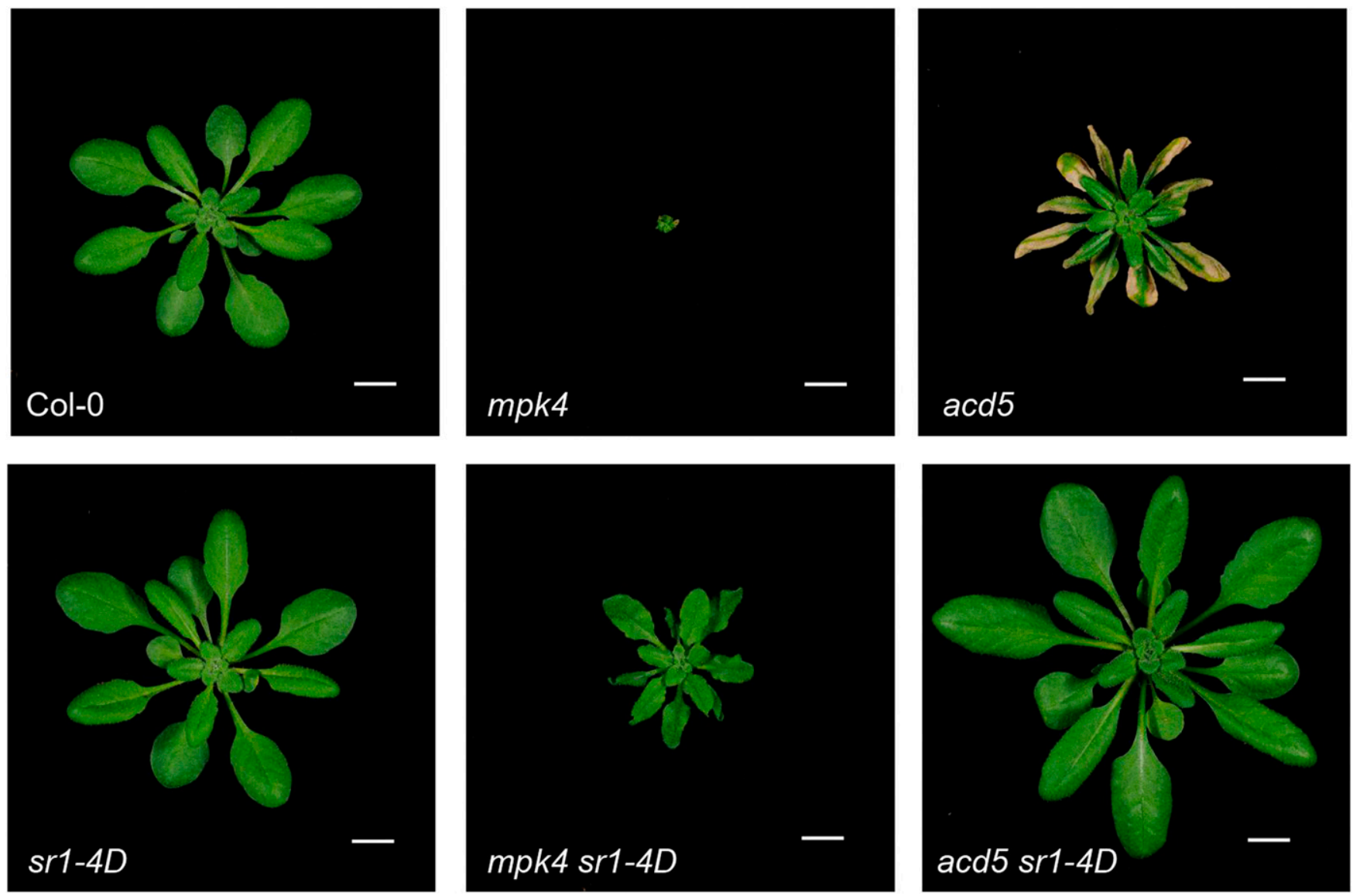

Fig. 8. SR1 is involved in both defense-gene and cell-death regulation. Growth phenotypes of wild type (Col-0), srl-4D, and constitutive defense mutant $m p k 4$ and lesion mimic mutant $a c d 5$ with crosses to $s r 1-4 D$ displaying the importance of SR 1 on cell-death regulation. Scale bar $=1 \mathrm{~cm}$. 
defenses. Strikingly, while coil nprl sid2 became resistant to $B$. cinerea, it remained as $\mathrm{O}_{3}$-sensitive as coil (Fig. 2; Supplementary Fig. S1). Thus, the mechanism governing $B$. cinerea tolerance seems to be specific to this pathogen response rather than regulation of ROS or PCD responses.

\section{Regulation of gene expression.}

In pathogen-defense signaling, the inhibitory action of SA on JA signaling is one of the best-studied interactions (Pieterse et al. 2012). However, numerous other interactions between signaling pathways have been documented. In relation to ET, JA, and SA, work with the dde ein 2 sid 2 pad4 quadruple mutant (and the corresponding single, double, and triple mutants), with impaired responses to the three hormones ( $d d e$ is also known as aos [allene oxide synthase], a required step in JA biosynthesis) and the defense regulator PAD4, has shown multiple interactions between the different signaling pathways after activation of defense signaling with flg22 (Hillmer et al. 2017). Strikingly, some interactions are observed only in higher order mutants, revealing buffering in defense signaling. For example, in some conditions, activation of SA signaling requires JA (Hillmer et al. 2017).

To study the interaction between hormone signaling pathways in B. cinerea infection and apoplastic ROS signaling, we selected marker genes that reveal the output of JA, SA, ET, and systemic signaling. Antagonistic interactions between SA and JA have been observed in several Arabidopsis-pathogen interactions (Koornneef et al. 2008) and in the regulation of cell death induced by exposure to $\mathrm{O}_{3}$-induced ROS (Overmyer et al. 2000, 2005). Compared with other Arabidopsis-pathogen systems, we observed relatively few interactions among the hormones after $B$. cinerea infection or $\mathrm{O}_{3}$ treatment. We did not see any interaction between JA and SA (or JA and ET) in regulation of JA markers $J A Z 1$ and RAP2.6 after B. cinerea infection (Fig. 5). Similarly, transcript levels for the ET marker ARGOS were not influenced by SA or JA (Fig. 6). In contrast, transcript levels for SA markers PR-1 and WRKY38 increased in ein2, indicating an inhibitory action of ET on SA signaling (Figs. 5 and 9) (Overmyer et al. 2018). The $\operatorname{axrl}$ mutant was included to evaluate the role of auxin and JA in defense signaling. In sterile growth conditions, this mutant was B. cinerea-susceptible (Llorente et al. 2008), but it was tolerant in our soil-grown plants (Fig. 1). In marker gene expression, axrl partially resembled coil with lowered transcript levels for $J A Z 1\left(\mathrm{O}_{3}\right.$ only), PDF1.1, PDF 1.2, and WRKY75 (Figs. 5 and 6), but another JA marker, RAP2.6, had similar transcript levels in WT and axrl, suggesting that this mutant is not as strongly JA-insensitive as coil.

We included the $s r l-4 D$ mutant in our experiments to further define its role in $B$. cinerea susceptibility and defense signaling. Marker genes for SA, JA, and ET did not display altered transcript levels, whereas $P D F 1.1$ and $P D F 1.2$ transcript levels were low in $s r 1-4 D$ (Figs. 5 and 6). Plant defensins have been proposed to contribute to the resistance against fungal infection through a variety of molecular functions including lipid binding, inhibition of protein synthesis and regulation of ion channel activity (Parisi et al. 2019). Recently, PDF1.1 was proposed to act as an apoplastic iron chelator, resulting in resistance to the necrotroph Pectobacterium carotovorum subsp. carotovorum (Hsiao et al. 2017). To gain a broader understanding of potential biological processes regulated by SR1 we crossed $s r 1-4 D$ with mutants defective in the control of SA, defense signaling ( $m p k 4$ ), and cell death (acd5). Double mutant analysis (Fig. 8) suggests that SR1 likely regulates some aspect of cell death execution. We propose that the high $B$. cinerea susceptibility of $s r l-4 D$ can be at least partially explained by its low expression of plant defensins. In addition, timing of execution of cell death could contribute to tolerance versus susceptibility (Cui et al. 2019).

\section{Local versus systemic signaling and}

\section{hormone cross-regulation.}

Plants must co-ordinate their defense responses across multiple tissues and organs (leaf-to-leaf, leaf-to-root). Systemic signaling between different parts of the plant is observed in both abiotic and biotic stresses and is proposed to be mediated by $\mathrm{ROS}, \mathrm{Ca}^{2+}$, electric, and other signals (Devireddy et al. 2020). GUS staining in promoter-GUS lines allowed us to observe the expression of selected marker genes spatially and in nontreated leaves. We did not observe systemic signaling at the timepoints or the treatments that we used. The locally contained expression indicates that, at least during early stages after stress initiation, the genes used here were not induced in other tissues. Possibly more sensitive methods would be needed to observe systemic signaling, either with more sensitive reporters (luciferase) or qPCR. Another hormone important in plant-pathogen interactions is ABA. Unfortunately, its exact function is difficult to study, as ABA biosynthesis or insensitive mutants display a defective cuticle that provides strong resistance to B. cinerea, independent of ABA signaling (Cui et al. 2019). Our ABCG40:GUS lines showed strong staining at the site of $B$. cinerea infection (and by the other treatments [Supplementary Fig. S5]). As ABCG40 is an ABA importer (Kang et al. 2010), this implies that local ABA signaling is initiated during $B$. cinerea infection. One additional piece of information was gained with reporter-GUS lines. Several of the JA reporters, JAZ1:GUS, PDF1.1:GUS, and RAP2.6:GUS, were regulated by the SA treatment (Fig. 7; Supplementary Fig. S5). This was consistent with Genevestigator data (RAP2.6) (Fig. 3) and increased transcript levels for $J A Z 1$ in the RNA-seq experiment with SA or the SA-analog benzothiadiazole treatments (Ding et al. 2018; Yang et al. 2017). Thus, while marker genes for JA (especially JAZ1 and RAP2.6) show dependency on COI1 (Figs. 5 and 6), they can also be induced by the SA treatment (Fig. 7; Supplementary Fig. S5), this illustrates the close connection of SA and JA signaling pathways.

Compared with other Arabidopsis-pathogen systems, we observed relatively few interactions among hormone signaling pathways (Fig. 9). This is consistent with the transcriptional response to $\mathrm{O}_{3}$-induced $\mathrm{ROS}$ with RNA-seq data from $\mathrm{O}_{3^{-}}$ treated coil ein 2 sid2, in which approximately $70 \%$ of $\mathrm{O}_{3^{-}}$ regulated genes show similar regulation in the triple mutant and WT (Xu et al. 2015). Similarly, one-third of flg22-regulated genes are independent of SA, JA, and ET signaling (Hillmer et al. 2017). Thus, despite the clear importance of stress hormones and their signaling pathways, a large proportion of defense signaling can occur independent of their contribution.

\section{MATERIALS AND METHODS}

\section{Plant material.}

All Arabidopsis accessions were of Col-0 background and were grown under a 12-h day and 12-h night cycle with irradiance of $120 \mu \mathrm{mol} \mathrm{m} \mathrm{m}^{-2} \mathrm{~s}^{-1}$ for $B$. cinerea experiments and $180 \mu \mathrm{mol} \mathrm{m}^{-2} \mathrm{~s}^{-1}$ for $\mathrm{O}_{3}$ experiments. During the day, humidity was kept at $65 \%$ and at $75 \%$ during the night. Growth medium was a 2:1 mixture of peat (Type B2; Kekkilä) and vermiculite. Plants were grown for three weeks for experiments.

Arabidopsis plants for gas-exchange measurements were grown in the growth chambers (AR-66LX and AR-22L, Percival Scientific, IA, USA) under 12-h day and 12-h night photoperiod, $23^{\circ} \mathrm{C}$ day and $18^{\circ} \mathrm{C}$ night temperature, $150 \mu \mathrm{mol}$ $1 \mathrm{~m}^{-2} \mathrm{~s}^{-1}$ light intensity, and $70 \%$ relative air humidity. Plants were grown in a soil mix that contained $4: 3$ peat and vermiculite.

The single, double, and triple mutant (coil-16, ein2-1, sid2-1) collection is described by Xu et al. (2015). The axrl and mpk4 
(SALK_056245) mutants were obtained from NASC (Nottingham Arabidopsis Stock Centre). The following mutants were gifts, nprl-1 (X. Dong), acd5 (J. Greenberg), and $s r 1-4 D$ (D. Tang) (Nie et al. 2012). New double mutants were constructed with coil-16 or $s r 1-4 D$ as pollen acceptors, homozygous mutants were identified with PCR-based markers (Supplementary Table $\mathrm{S} 1$ ) in F2 and were confirmed in F3 generations. The coil-16 mutants used in this study were previously backcrossed to Col0 to remove second site mutations (Xu et al. 2015).

\section{Construction of promoter reporter plants.}

The promoters of PME17, ABCG40, PDF1.1, and At4g16260 were amplified from genomic DNA (Col-0) by PCR and were cloned into the $\mathrm{pENTR/D-TOPO}$ vector. Primers used for the cloning are listed in Supplementary Table S2. The promoters were recombined with Gateway technology (ThermoFisher Scientific) into the binary pGypsy vector that gives EGFP and GUS as reporters (She et al. 2010). The resulting vectors were introduced into Agrobacterium tumefaciens GV3101::pMP90 and then into Arabidopsis thaliana Col-0 wild-type plants using the floral dip method (Clough and Bent 1998).

Additional promoter-GUS lines were obtained from NASC (N799792 JAZ1/TIFY10A:GUS line 9) or were gifts, ICS1:GUS (J. Carr [Lewsey et al. 2010]), RAP2.6:GUS (H. Bohlmann [Ali et al. 2013]), and WRKY75:GUS (M. Hülskamp [Rishmawi et al. 2014]).

\section{Fungal culture and infection protocol.}

Botrytis cinerea B05.10 was grown on nutrient-rich homemade potato-carrot agar plates. For 1 liter of growth media, $300 \mathrm{~g}$ of potato, $25 \mathrm{~g}$ of carrot, and $50 \mathrm{~g}$ of tomato were grated and were boiled in Milli-Q (MQ) water for $20 \mathrm{~min}$ and were then strained, keeping the liquid fraction; $10 \mathrm{~g}$ of dextrose, $1.5 \mathrm{~g}$ of yeast extract, and $15 \mathrm{~g}$ of agar were added into the base and the volume was adjusted to 1 liter with MQ water before autoclaving and plate pouring. Plates were inoculated with a small piece of hyphal mass with growth media from an older culture. Inoculated plates were kept at ambient room temperature in darkness until ready for experiments at 3 weeks to 2 months.

B. cinerea sporulation mass was harvested from plates, using sterilized forceps, into half-strength potato-dextrose broth (PDB). For all infections, the spore count was adjusted to $1 \times$ $10^{6}$ spores per milliliter of half-strength PDB. After infection, both treated and control plants were sealed in mini-greenhouses to maintain high humidity and were placed back to normal growth conditions.

For phenotyping assays, the inoculum was pipetted onto leaves as 3- $\mu \mathrm{l}$ drops. One drop of inoculum was pipetted per leaf and two or three leaves were infected per plant. Number of infected leaves was determined by the plant size. Infected leaves were expanded but did not show any signs of senescence. At $48 \mathrm{hpi}$, infected leaves were cut from the rosette and were photographed. Lesions were measured from the photographs in ImageJ (version $1.47 \mathrm{v})$ and the data were later analyzed in RStudio.

For the qPCR assays, plants were sprayed with either inoculum $\left(1 \times 10^{6}\right.$ spores per milliliter of half-strength PDB) or with half-strength PDB. Whole rosettes were collected at 18 or at $24 \mathrm{hpi}$ and were directly frozen in liquid nitrogen.

\section{Ozone treatments.}

For ozone gene-expression experiments, plants were treated with $350 \mathrm{nl}$ of ozone per liter for $2 \mathrm{~h}$. Control plants remained in fresh air conditions during the exposure. For cell death measurements, plants were treated with $350 \mathrm{nl}$ of ozone per liter for 6 $\mathrm{h}$, and the extent of cell death was quantified, at $8 \mathrm{~h}$ from the start of the ozone treatment, with ion leakage (Brosché et al. 2014).

\section{Wounding, JA, and SA treatments.}

Wounding assays were performed by making a small cut in one leaf with a scalpel and by partially crushing two leaves with forceps per plant. Crushing was performed hard enough to leave visible damage.

Hormonal treatments, $500 \mu \mathrm{M}$ SA or $100 \mu \mathrm{M}$ methyl-JA, were performed by pipetting a $15-\mu$ l drop of hormone solution onto two or three leaves per plant, depending on the plant size.

\section{Gas-exchange measurements.}

Changes in stomatal conductance during response to ozone were monitored using a custom made gas-exchange device (Brosché et al. 2010). Col-0 and axrl plants were stabilized for $1 \mathrm{~h}$ before experiments in chambers under $150 \mu \mathrm{mol} \mathrm{m} \mathrm{m}^{-2} \mathrm{~s}^{-1}$ light intensity and $70 \%$ relative air humidity. Plants were treated with approximately $400 \mathrm{nl}$ of ozone per liter continuously for $4 \mathrm{~h}$.

\section{Analysis of RNA-seq data.}

The analysis of the RNA-seq data was done as previously described (Xu et al. 2015), with 2-h $\mathrm{O}_{3}$ data from Xu et al. (2015) (Gene Expression Omnibus [GEO] accession GSE65740) and 14-h B. cinerea data from Liu et al. (2015) (GEO accession GSE66300). Genes were selected at $q<0.05$ and twofold regulation (Supplementary Table S3).

\section{Real time reverse transcription qPCR.}

Transcript abundance of selected marker genes after B. cinerea infection (18 and $24 \mathrm{hpi}$ ) and $\mathrm{O}_{3}$ treatment $(2 \mathrm{~h})$ was measured with qPCR, using three biological repeats. Each biological repeat consisted of five plants treated with inoculum solution or with control spray (lacking Botrytis cinerea spores) or with clean-air controls or $350 \mathrm{nl}$ of ozone per liter. RNA was isolated with GeneJET plant RNA purification kit (ThermoFisher Scientific). Two micrograms of RNA was DNAseItreated and cDNA synthesis was performed with Maxima reverse transcription according to manufacturer instructions (ThermoFisher Scientific). qPCR was performed with $5 \times$ HOT FIREPol EvaGreen qPCR Mix Plus (Solis Biodyne) on a CFX384 Touch real-time PCR detection system (Bio-Rad). Primer sequences and primer efficiencies are listed in Supplementary Table S2. To normalize the qPCR data three different references genes were tested and validated with geNorm to have stable expression in the samples used in this study (PP2AA3, TIP41, and YLS8). Calculation of relative expression and normalization was done in qBase+ 3.2 (Biogazelle).

\section{GUS-staining.}

For GUS staining, whole rosettes were collected and stained. The rosette was cut below the neck of the root, to ensure the rosettes stayed intact, and was placed immediately into cold acetone after harvesting. Samples were washed three times with cold Na-phosphate $(50 \mathrm{mM}, 7.2 \mathrm{pH}, 1 \mathrm{~h}$ per wash) before staining solution was added (for $500 \mathrm{ml}: 15 \mathrm{ml}$ of $1 \mathrm{M} \mathrm{Na}_{2} \mathrm{HPO}_{4}, 10 \mathrm{ml}$ $1 \mathrm{M} \mathrm{NaH} \mathrm{PO}_{4}, 105 \mathrm{mg} \mathrm{K}\left[\mathrm{Fe}(\mathrm{CN})_{6}\right] \times 3 \mathrm{H}_{2} \mathrm{O}, 82 \mathrm{mg}$ $\mathrm{K}_{3}\left[\mathrm{Fe}(\mathrm{CN})_{6}\right], 250 \mathrm{mg} \mathrm{X}$-Gluc, dissolved in $1 \mathrm{ml}$ dimethylformamide, $0.5 \mathrm{ml}$ Triton X-100). Samples were placed in a vacuum for $5 \mathrm{~min}$ and were then allowed to stain overnight in room temperature. Afterwards, staining samples were stored in $100 \%$ ethanol until scanning, for which they were transferred to $50 \%$ glycerol.

\section{Statistical analysis.}

Lesion sizes from phenotyping experiments were measured in Image J (Schneider et al. 2012) (version 1.47v). Statistical analysis was performed in RStudio version 1.1 .383 with $\mathrm{R}$ (2017, version 3.4.0), using nlme (version 3.1-131 [Pinheiro 
et al. 2017]), multcomp (Hothorn et al. 2008), plyr (Wickham 2011), and ggplot2 (Wickham 2016) packages.

\section{ACKNOWLEDGMENTS}

We thank L. Kale, T. Puukko, A. Lamminmäki, and L. Grönholm for excellent technical support and M. Sierla, J. Krasensky-Wrzaczek, and C. Waszczak for comments on the manuscript.

\section{AUTHOR-RECOMMENDED INTERNET RESOURCES}

The Arabidopsis Information Resource (TAIR): https://www.arabidopsis.org Gene Expression Omnibus database: https://www.ncbi.nlm.nih.gov/geo

\section{LITERATURE CITED}

Ali, M. A., Abbas, A., Kreil, D. P., and Bohlmann, H. 2013. Overexpression of the transcription factor RAP2.6 leads to enhanced callose deposition in syncytia and enhanced resistance against the beet cyst nematode Heterodera schachtii in Arabidopsis roots. BMC Plant Biol. 13:47.

Asselbergh, B., Curvers, K., França, S. C., Audenaert, K., Vuylsteke, M., Van Breusegem, F., and Höfte, M. 2007. Resistance to Botrytis cinerea in sitiens, an abscisic acid-deficient tomato mutant, involves timely production of hydrogen peroxide and cell wall modifications in the epidermis. Plant Physiol. 144:1863-1877.

Blomster, T., Salojärvi, J., Sipari, N., Brosché, M., Ahlfors, R., Keinänen, M., Overmyer, K., and Kangasjärvi, J. 2011. Apoplastic reactive oxygen species transiently decrease auxin signaling and cause stress-induced morphogenic response in Arabidopsis. Plant Physiol. 157:1866-1883.

Brosché, M., Blomster, T., Salojärvi, J., Cui, F., Sipari, N., Leppälä, J., Lamminmäki, A., Tomai, G., Narayanasamy, S., Reddy, R. A., Keinänen, M., Overmyer, K., and Kangasjärvi, J. 2014. Transcriptomics and functional genomics of ROS-induced cell death regulation by RADICALINDUCED CELL DEATH1. PLoS Genet. 10:e1004112.

Brosché, M., Merilo, E., Mayer, F., Pechter, P., Puzõrjova, I., Brader, G., Kangasjärvi, J., and Kollist, H. 2010. Natural variation in ozone sensitivity among Arabidopsis thaliana accessions and its relation to stomatal conductance. Plant Cell Environ. 33:914-925.

Clough, S. J., and Bent, A. F. 1998. Floral dip: A simplified method for Agrobacterium-mediated transformation of Arabidopsis thaliana. Plant J. 16:735-743.

Cui, F., Wu, W., Wang, K., Zhang, Y., Hu, Z., Brosché, M., Liu, S., and Overmyer, K. 2019. Cell death regulation but not abscisic acid signaling is required for enhanced immunity to Botrytis in Arabidopsis cuticlepermeable mutants. J. Exp. Bot. 70:5971-5984.

Denness, L., McKenna, J. F., Segonzac, C., Wormit, A., Madhou, P., Bennett, M., Mansfield, J., Zipfel, C., and Hamann, T. 2011. Cell wall damage-induced lignin biosynthesis is regulated by a reactive oxygen species- and jasmonic acid-dependent process in Arabidopsis. Plant Physiol. 156:1364-1374.

Devireddy, A. R., Arbogast, J., and Mittler, R. 2020. Coordinated and rapid whole-plant systemic stomatal responses. New Phytol. 225:21-25.

Dharmasiri, N., Dharmasiri, S., Weijers, D., Karunarathna, N., Jurgens, G., and Estelle, M. 2007. AXL and AXR1 have redundant functions in RUB conjugation and growth and development in Arabidopsis. Plant J. 52: 114-123.

Ding, Y., Sun, T., Ao, K., Peng, Y., Zhang, Y., Li, X., and Zhang, Y. 2018. Opposite roles of salicylic acid receptors NPR1 and NPR3/NPR4 in transcriptional regulation of plant immunity. Cell 173:1454-1467.

Du, L., Ali, G. S., Simons, K. A., Hou, J., Yang, T., Reddy, A. S. N., and Poovaiah, B. W. 2009. $\mathrm{Ca}^{2+} /$ calmodulin regulates salicylic-acidmediated plant immunity. Nature 457:1154-1158.

Durian, G., Jeschke, V., Rahikainen, M., Vuorinen, K., Gollan, P. J., Brosché, M., Salojärvi, J., Glawischnig, E., Winter, Z., Li, S., Noctor, G., Aro, E. M., Kangasjärvi, J., Overmyer, K., Burow, M., and Kangasjärvi, S. 2020. PROTEIN PHOSPHATASE 2A-B' $\gamma$ controls Botrytis cinerea resistance and developmental leaf senescence. Plant Physiol. 182: 1161-1181.

Durian, G., Rahikainen, M., Alegre, S., Brosché, M., and Kangasjärvi, S. 2016. Protein phosphatase $2 \mathrm{~A}$ in the regulatory network underlying biotic stress resistance in plants.Front. Plant Sci. 7:812.

Ferrari, S., Plotnikova, J. M., de Lorenzo, G., and Ausubel, F. M. 2003. Arabidopsis local resistance to Botrytis cinerea involves salicylic acid and camalexin and requires EDS4 and PAD2, but not SID2, EDS5 or PAD4. Plant J. 35:193-205.
Glazebrook, J. 2005. Contrasting mechanisms of defense against biotrophic and necrotrophic pathogens. Annu. Rev. Phytopathol. 43:205-227.

Govrin, E. M., and Levine, A. 2000. The hypersensitive response facilitates plant infection by the necrotrophic pathogen Botrytis cinerea. Curr. Biol. 10:751-757.

Hartmann, M., Zeier, T., Bernsdorff, F., Reichel-Deland, V., Kim, D., Hohmann, M., Scholten, N., Schuck, S., Bräutigam, A., Hölzel, T. Ganter, C., and Zeier, J. 2018. Flavin monooxygenase-generated Nhydroxypipecolic acid is a critical element of plant systemic immunity. Cell 173:456-469.

Hickman, R., Mendes, M. P., Van Verk, M. C., Van Dijken, A. J. H., di Sora, J., Denby, K., Pieterse, C. M. J., and Van Wees, S. C. M. 2019 Transcriptional dynamics of the salicylic acid response and its interplay with the jasmonic acid pathway. bioRxiv 742742 .

Hillmer, R. A., Tsuda, K., Rallapalli, G., Asai, S., Truman, W., Papke, M. D., Sakakibara, H., Jones, J. D. G., Myers, C. L., and Katagiri, F 2017. The highly buffered Arabidopsis immune signaling network conceals the functions of its components. PLOS Genet. 13:e1006639.

Hothorn, T., Bretz, F., and Westfall, P. 2008. Simultaneous inference in general parametric models. Biom. J. 50:346-363.

Hruz, T., Laule, O., Szabo, G., Wessendorp, F., Bleuler, S., Oertle, L., Widmayer, P., Gruissem, W., and Zimmermann, P. 2008. Genevestigator v3: A reference expression database for the meta-analysis of transcriptomes. Adv. Bioinformatics 2008:420747.

Hsiao, P. Y., Cheng, C. P., Koh, K. W., and Chan, M. T. 2017. The Arabidopsis defensin gene, AtPDF1.1, mediates defence agains Pectobacterium carotovorum subsp. carotovorum via an ironwithholding defence system. Sci. Rep. 7:9175.

Jacob, F., Kracher, B., Mine, A., Seyfferth, C., Blanvillain-Baufumé, S., Parker, J. E., Tsuda, K., Schulze-Lefert, P., and Maekawa, T. 2018. A dominant-interfering camta3 mutation compromises primary transcriptional outputs mediated by both cell surface and intracellular immune receptors in Arabidopsis thaliana. New Phytol. 217:1667-1680.

Kang, J., Hwang, J. U., Lee, M., Kim, Y. Y., Assmann, S. M., Martinoia, E., and Lee, Y. 2010. PDR-type ABC transporter mediates cellular uptake of the phytohormone abscisic acid. Proc. Natl. Acad. Sci. U.S.A. 107: 2355-2360

Kaurilind, E., and Brosché, M. 2017. Stress marker signatures in lesion mimic single and double mutants identify a crucial leaf age-dependent salicylic acid related defense signal. PLoS One 12:e0170532.

Koornneef, A., Leon-Reyes, A., Ritsema, T., Verhage, A., Den Otter, F. C., Van Loon, L. C., and Pieterse, C. M. J. 2008. Kinetics of salicylatemediated suppression of jasmonate signaling reveal a role for redox modulation. Plant Physiol. 147:1358-1368.

Lefevere, H., Bauters, L., and Gheysen, G. 2020. Salicylic acid biosynthesis in plants. Front. Plant Sci. 11:338.

Lewsey, M. G., Murphy, A. M., Maclean, D., Dalchau, N., Westwood, J. H., Macaulay, K., Bennett, M. H., Moulin, M., Hanke, D. E., Powell, G., Smith, A. G., and Carr, J. P. 2010. Disruption of two defensive signaling pathways by a viral RNA silencing suppressor. Mol. Plant-Microbe Interact 23:835-845.

Leyser, O. 2018. Auxin Signaling. Plant Physiol. 176:465-479.

Liang, H., Yao, N., Song, J. T., Luo, S., Lu, H., and Greenberg, J. T. 2003. Ceramides modulate programmed cell death in plants. Genes Dev. 17: 2636-2641.

Liu, L., Sonbol, F. M., Huot, B., Gu, Y., Withers, J., Mwimba, M., Yao, J., He, S. Y., and Dong, X. 2016. Salicylic acid receptors activate jasmonic acid signalling through a non-canonical pathway to promote effectortriggered immunity. Nat. Commun. 7:13099.

Liu, S., Kracher, B., Ziegler, J., Birkenbihl, R. P., and Somssich, I. E. 2015. Negative regulation of ABA signaling by WRKY33 is critical for Arabidopsis immunity towards Botrytis cinerea 2100. eLife 4:e07295.

Llorente, F., Muskett, P., Sánchez-Vallet, A., López, G., Ramos, B., Sánchez-Rodríguez, C., Jordá, L., Parker, J., and Molina, A. 2008 Repression of the auxin response pathway increases Arabidopsis susceptibility to necrotrophic fungi. Mol. Plant 1:496-509.

Méndez-Bravo, A., Calderón-Vázquez, C., Ibarra-Laclette, E., RayaGonzález, J., Ramírez-Chávez, E., Molina-Torres, J., Guevara-García, A. A., López-Bucio, J., and Herrera-Estrella, L. 2011. Alkamides activate jasmonic acid biosynthesis and signaling pathways and confer resistance to Botrytis cinerea in Arabidopsis thaliana. PLoS One 6: e27251.

Mengiste, T., Chen, X., Salmeron, J., and Dietrich, R. 2003. The BOTRYTIS SUSCEPTIBLE1 gene encodes an R2R3MYB transcription factor protein that is required for biotic and abiotic stress responses in Arabidopsis. Plant Cell 15:2551-2565.

Moura, J. C. M. S., Bonine, C. A. V., de Oliveira Fernandes Viana, J. Dornelas, M. C., and Mazzafera, P. 2010. Abiotic and biotic stresses and 
changes in the lignin content and composition in plants. J. Integr. Plant Biol. 52:360-376

Nie, H., Zhao, C., Wu, G., Wu, Y., Chen, Y., and Tang, D. 2012. SR1, a calmodulin-binding transcription factor, modulates plant defense and ethylene-induced senescence by directly regulating NDRI and EIN3. Plant Physiol. 158:1847-1859.

Overmyer, K., Brosché, M., Pellinen, R., Kuittinen, T., Tuominen, H., Ahlfors, R., Keinänen, M., Saarma, M., Scheel, D., and Kangasjärvi, J. 2005. Ozone-induced programmed cell death in the Arabidopsis radicalinduced cell death1 mutant. Plant Physiol. 137:1092-1104.

Overmyer, K., Tuominen, H., Kettunen, R., Betz, C., Langebartels, C., Sandermann, H., Jr., and Kangasjärvi, J. 2000. Ozone-sensitive Arabidopsis rcdl mutant reveals opposite roles for ethylene and jasmonate signaling pathways in regulating superoxide-dependent cell death. Plant Cell 12:1849-1862.

Overmyer, K., Vuorinen, K., and Brosché, M. 2018. Interaction points in plant stress signaling pathways. Physiol. Plant. 162:191-204.

Parisi, K., Shafee, T. M. A., Quimbar, P., van der Weerden, N. L., Bleackley, M. R., and Anderson, M. A. 2019. The evolution, function and mechanisms of action for plant defensins. Semin. Cell Dev. Biol. 88:107-118.

Petersen, M., Brodersen, P., Naested, H., Andreasson, E., Lindhart, U., Johansen, B., Nielsen, H. B., Lacy, M., Austin, M. J., Parker, J. E., Sharma, S. B., Klessig, D. F., Martienssen, R., Mattsson, O., Jensen, A. B., and Mundy, J. 2000. Arabidopsis map kinase 4 negatively regulates systemic acquired resistance. Cell 103:1111-1120.

Pieterse, C. M. J., Van der Does, D., Zamioudis, C., Leon-Reyes, A., and Van Wees, S. C. M. 2012. Hormonal modulation of plant immunity. Annu. Rev. Cell Dev. Biol. 28:489-521.

Pinheiro, J., Bates, D., DebRoy, S., and Sarkar, D. 2017. nlme: Linear and nonlinear mixed effects models. R package version 3.1-131. CRAN-R, Vienna, Austria.

Qiao, H., Shen, Z., Huang, S. S. C., Schmitz, R. J., Urich, M. A., Briggs, S. P., and Ecker, J. R. 2012. Processing and subcellular trafficking of ERtethered EIN2 control response to ethylene gas. Science 338:390-393.

Rishmawi, L., Pesch, M., Juengst, C., Schauss, A. C., Schrader, A., and Hülskamp, M. 2014. Non-cell-autonomous regulation of root hair patterning genes by WRKY75 in Arabidopsis. Plant Physiol. 165:186-195.

Schneider, C. A., Rasband, W. S., and Eliceiri, K. W. 2012. NIH Image to ImageJ: 25 years of image analysis. Nat. Methods 9:671-675.

Serrano, M., Coluccia, F., Torres, M., L'Haridon, F., and Métraux, J. P. 2014. The cuticle and plant defense to pathogens. Front. Plant Sci. 5:274.

She, W., Lin, W., Zhu, Y., Chen, Y., Jin, W., Yang, Y., Han, N., Bian, H., Zhu, M., and Wang, J. 2010. The gypsy insulator of Drosophila melanogaster, together with its binding protein suppressor of hairy-wing, facilitate high and precise expression of transgenes in Arabidopsis thaliana. Genetics 185:1141-1150.

Siegmund, U., and Viefhues, A. 2016. Reactive oxygen species in the Botrytis-host interaction. Pages 269-289 in: Botrytis-The Fungus, the Pathogen and Its Management in Agricultural Systems. S. Fillinger, and Y. Elad, eds. Springer International Publishing, Cham, Switzerland.

Stintzi, A., Weber, H., Reymond, P., Browse, J., and Farmer, E. E. 2001. Plant defense in the absence of jasmonic acid: The role of cyclopentenones. Proc. Natl. Acad. Sci. U.S.A. 98:12837-12842.

Survila, M., Davidsson, P. R., Pennanen, V., Kariola, T., Broberg, M., Sipari, N., Heino, P., and Palva, E. T. 2016. Peroxidase-generated apoplastic ROS impair cuticle integrity and contribute to DAMP-elicited defenses. Front. Plant Sci. 7:1945.

Tan, S., Abas, M., Verstraeten, I., Glanc, M., Molnár, G., Hajný, J., Lasák, P., Petř́k, I., Russinova, E., Petrášek, J., Novák, O., Pospíšil, J., and Friml, J. 2020. Salicylic acid targets protein phosphatase 2A to attenuate growth in plants. Curr. Biol. 30:381-395.

Thomma, B. P. H. J., Cammue, B. P. A., and Thevissen, K. 2002. Plant defensins. Planta 216:193-202.

Tiryaki, I., and Staswick, P. E. 2002. An Arabidopsis mutant defective in jasmonate response is allelic to the auxin-signaling mutant axr1. Plant Physiol. 130:887-894.

Torres, M. A. 2010. ROS in biotic interactions. Physiol. Plant. 138:414-429.

Tsuda, K., Sato, M., Stoddard, T., Glazebrook, J., and Katagiri, F. 2009. Network properties of robust immunity in plants. PLoS Genet. 5: e1000772.

Wang, D., Amornsiripanitch, N., and Dong, X. 2006. A genomic approach to identify regulatory nodes in the transcriptional network of systemic acquired resistance in plants. PLoS Pathog. 2:e123.

Wang, D., Pajerowska-Mukhtar, K., Culler, A. H., and Dong, X. 2007. Salicylic acid inhibits pathogen growth in plants through repression of the auxin signaling pathway. Curr. Biol. 17:1784-1790.

Wickham, H. 2011. The split-apply-combine strategy for data analysis. J. Stat. Softw. 40:1-29.

Wickham, H. 2016. ggplot2: Elegant Graphics for Data Analysis. SpringerVerlag, Berlin.

Wildermuth, M. C., Dewdney, J., Wu, G., and Ausubel, F. M. 2001. Isochorismate synthase is required to synthesize salicylic acid for plant defence. Nature 414:562-565.

Williamson, B., Tudzynski, B., Tudzynski, P., and van Kan, J. A. L. 2007. Botrytis cinerea: The cause of grey mould disease. Mol. Plant Pathol. 8: 561-580.

Wohlgemuth, H., Mittelstrass, K., Kschieschan, S., Bender, J., Weigel, H. J., Overmyer, K., Kangasjärvi, J., Sandermann, H., and Langebartels, C. 2002. Activation of an oxidative burst is a general feature of sensitive plants exposed to the air pollutant ozone. Plant Cell Environ. 25: 717-726.

Xu, E., Vaahtera, L., and Brosché, M. 2015. Roles of defense hormones in the regulation of ozone-induced changes in gene expression and cell death. Mol. Plant 8:1776-1794.

Yan, S., Wang, W., Marqués, J., Mohan, R., Saleh, A., Durrant, W. E., Song, J., and Dong, X. 2013. Salicylic acid activates DNA damage responses to potentiate plant immunity. Mol. Cell 52:602-610.

Yang, L., Teixeira, P. J. P. L., Biswas, S., Finkel, O. M., He, Y., SalasGonzalez, I., English, M. E., Epple, P., Mieczkowski, P., and Dangl, J. L. 2017. Pseudomonas syringae type III effector HopBB1 promotes host transcriptional repressor degradation to regulate phytohormone responses and virulence. Cell Host Microbe 21:156-168.

Yuan, H. M., Liu, W. C., and Lu, Y. T. 2017. CATALASE2 coordinates SAmediated repression of both auxin accumulation and JA biosynthesis in plant defenses. Cell Host Microbe 21:143-155.

Zhang, W., Corwin, J. A., Copeland, D., Feusier, J., Eshbaugh, R., Chen, F., Atwell, S., and Kliebenstein, D. J. 2017. Plastic transcriptomes stabilize immunity to pathogen diversity: The jasmonic acid and salicylic acid networks within the Arabidopsis/Botrytis pathosystem. Plant Cell 29: 2727-2752. 